\title{
Article \\ The Importance of Thermal Treatment on Wet-Kneaded Silica-Magnesia Catalyst and Lebedev Ethanol-to-Butadiene Process
}

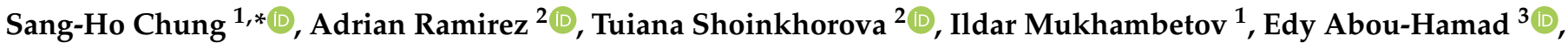 \\ Selevedin Telalovic ${ }^{2}$, Jorge Gascon ${ }^{2}$ and Javier Ruiz-Martínez ${ }^{1, *}$
}

Citation: Chung, S.-H.; Ramirez, A.; Shoinkhorova, T.; Mukhambetov, I.; Abou-Hamad, E.; Telalovic, S.; Gascon, J.; Ruiz-Martínez, J. The Importance of Thermal Treatment on Wet-Kneaded Silica-Magnesia Catalyst and Lebedev Ethanol-to-Butadiene Process. Nanomaterials 2021, 11, 579. https://doi.org/nano11030579

Academic Editor: Juan Carlos Serrano-Ruiz

Received: 31 December 2020

Accepted: 11 February 2021

Published: 26 February 2021

Publisher's Note: MDPI stays neutral with regard to jurisdictional claims in published maps and institutional affiliations.

Copyright: (c) 2021 by the authors. Licensee MDPI, Basel, Switzerland. This article is an open access article distributed under the terms and conditions of the Creative Commons Attribution (CC BY) license (https:/ / creativecommons.org/licenses/by/ $4.0 /)$.
1 KAUST Catalysis Center, King Abdullah University of Science and Technology, Catalysis, Nanomaterials, and Spectroscopy (CNS), Thuwal 23955, Saudi Arabia; ildar.mukhambetov@kaust.edu.sa

2 KAUST Catalysis Center, King Abdullah University of Science and Technology, Advanced Catalytic Materials (ACM), Thuwal 23955, Saudi Arabia; adrian.galilea@kaust.edu.sa (A.R.); tuiana.shoinkhorova@kaust.edu.sa (T.S.); selvedin.telalovic@kaust.edu.sa (S.T.); jorge.gascon@kaust.edu.sa (J.G.)

3 KAUST Core Labs, King Abdullah University of Science and Technology, Thuwal 23955, Saudi Arabia; edy.abouhamad@kaust.edu.sa

* Correspondence: sangho.chung@kaust.edu.sa (S.-H.C.); javier.ruizmartinez@kaust.edu.sa (J.R.-M.); Tel.: +966-(0)12-808-4530 (J.R.-M.)

\begin{abstract}
The Lebedev process, in which ethanol is catalytically converted into 1,3-butadiene, is an alternative process for the production of this commodity chemical. Silica-magnesia $\left(\mathrm{SiO}_{2}-\mathrm{MgO}\right)$ is a benchmark catalyst for the Lebedev process. Among the different preparation methods, the $\mathrm{SiO}_{2}-$ $\mathrm{MgO}$ catalysts prepared by wet-kneading typically perform best owing to the surface magnesium silicates formed during wet-kneading. Although the thermal treatment is of pivotal importance as a last step in the catalyst preparation, the effect of the calcination temperature of the wet-kneaded $\mathrm{SiO}_{2}-\mathrm{MgO}$ on the Lebedev process has not been clarified yet. Here, we prepared and characterized in detail a series of wet-kneaded $\mathrm{SiO}_{2}-\mathrm{MgO}$ catalysts using varying calcination temperatures. We find that the thermal treatment largely influences the type of magnesium silicates, which have different catalytic properties. Our results suggest that the structurally ill-defined amorphous magnesium silicates and lizardite are responsible for the production of ethylene. Further, we argue that forsterite, which has been conventionally considered detrimental for the formation of ethylene, favors the formation of butadiene, especially when combined with stevensite.
\end{abstract}

Keywords: ethanol; butadiene; Lebedev process; wet-kneading; silica-magnesia; magnesium silicate

\section{Introduction}

1,3-Butadiene (butadiene) is an essential C4 monomer in the polymer industry for styrene-butadiene rubber (SBR), acrylonitrile-butadiene-styrene rubber (ABS), and polybutadiene-styrene (PBS). Butadiene is currently produced as a byproduct in naphtha steam crackers [1]. Thus, there is a strong dependence on the price of ethylene (the main product of naphtha steam cracking) [2-5], with the recent increase in shale gas usage potentially leading to butadiene shortage in the global chemical market $[1,6]$. There has been a growing need for on-purpose, sustainable processes for butadiene. The Lebedev process is one such promising candidates owing to its innate "target-specific" for butadiene from ethanol. In addition, given the recent increased availability of bio-ethanol [7], a sustainable butadiene process is particularly attractive.

Although the actual reaction mechanism of the Lebedev process is still under discussion, the aldol condensation mechanism proposed by Toussaint et al. is one of the most plausible ones [2,8]: ethanol is first converted into acetaldehyde by dehydrogenation and aldol condensation between two acetaldehyde forms of 3-hydroxybutanal; subsequent 
dehydration and hydrogenation yields crotonaldehyde and crotonyl alcohol, respectively; and finally, butadiene is obtained by dehydration (Scheme 1). These multistep conversions require a multifunctional catalyst, and the interplay of acid/base and redox properties of the catalyst plays a crucial role in achieving a high butadiene yield.

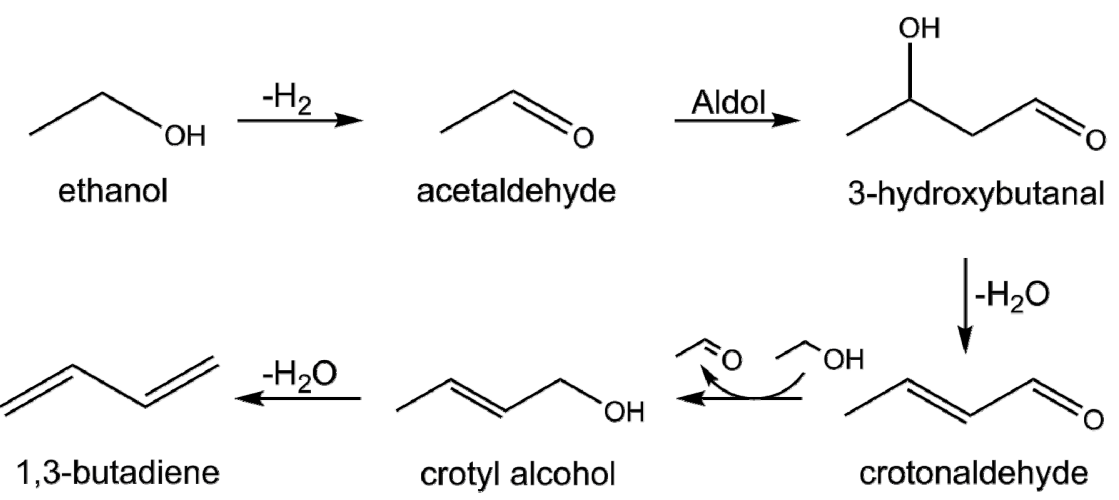

Scheme 1. The commonly proposed reaction mechanism of the Lebedev process via the aldol condensation route.

Various metal-promoted catalysts were recently studied in the Lebedev process such as $\mathrm{M}-\mathrm{Ta} / \mathrm{BEA}(\mathrm{M}=\mathrm{Ag}, \mathrm{Cu}$, and $\mathrm{Zn})$ [9], $\mathrm{Zn}-\mathrm{Y} / \mathrm{BEA}$ (5\% $\mathrm{Zn}$ and 5\% Y) [10], $\mathrm{Cu}$ or $\mathrm{Zn} / \mathrm{MgO}$ $\mathrm{SiO}_{2}$ [11], $\mathrm{Hf}-\mathrm{Zn} / \mathrm{SiO}_{2}$ [12], and $\mathrm{Ga} / \mathrm{Mg}-\mathrm{SiO}_{2}(5 \% \mathrm{Ga}$ and $\mathrm{Si} / \mathrm{Mg}=1)$ [13]. Ta, $\mathrm{Y}$, and $\mathrm{Mg}$ can alter the acid/base properties, while the second metals such as $\mathrm{Ag}, \mathrm{Cu}, \mathrm{Zn}, \mathrm{Hf}$, and $\mathrm{Ga}$ improve the redox properties of the catalysts. Although promotion of the redox function by a second metal can enhance the dehydrogenation activity and butadiene selectivity, metalpromoted catalysts often show fast deactivation within $24 \mathrm{~h}$ time-on-stream due to the considerable amount of carbon deposition and/or agglomeration of the metal species [14].

$\mathrm{SiO}_{2}-\mathrm{MgO}$ catalysts are benchmark catalysts for the Lebedev process [15-17]. The preparation method of the $\mathrm{SiO}_{2}-\mathrm{MgO}$ catalyst is crucial for its catalytic performance. For example, the physical mixture of $\mathrm{SiO}_{2}$ and $\mathrm{MgO}$ shows much worse catalytic performance when compared to the coprecipitated $\mathrm{SiO}_{2}-\mathrm{MgO}$ [15]. Impregnation of magnesium species on mesoporous silica (MgO promoted SBA-15) efficiently converts ethanol into acetaldehyde due to the formation of moderate-strength $\mathrm{Mg}^{2+}-\mathrm{O}^{2-}$ Lewis acid-base site pairs at the expense of strongly basic $\mathrm{MgO}$ sites, stabilizing the transition state of adsorbed ethanol [17]. However, these MgO-promoted SBA-15 catalysts could not yield butadiene.

$\mathrm{SiO}_{2}-\mathrm{MgO}$ catalysts prepared by wet-kneading showed better catalytic performance, not only in terms of ethanol conversion but also in butadiene selectivity $[15,18]$. During wet-kneading, various types of magnesium silicates are formed by partial dissolution of individual $\mathrm{SiO}_{2}$ and $\mathrm{Mg}(\mathrm{OH})_{2}$ components (i.e., $\left[\mathrm{SiO}_{2}(\mathrm{OH})_{2}\right]^{2-}$ and $\left[\mathrm{Mg}\left(\mathrm{H}_{2} \mathrm{O}\right)_{6}\right]^{2+}$ ) in a basic wet-kneading solution $(\mathrm{pH}>9)$. The opposite surface charge of wet-kneading precursors have the dissolved ions cross-deposited on the surfaces [19]. As a result, a minimum of five different magnesium silicate polymorphs are formed, such as talc $\left(\mathrm{Mg}_{3} \mathrm{Si}_{4} \mathrm{O}_{10}(\mathrm{OH})_{2}\right)$, lizardite $\left(\mathrm{Mg}_{3} \mathrm{Si}_{2} \mathrm{O}_{5}(\mathrm{OH})_{4}\right)$, and stevensite $\left(\mathrm{Mg}_{\mathrm{x}}\left(\mathrm{Mg}_{3-\mathrm{x}} \square \mathrm{x}\right) \mathrm{Si}_{4} \mathrm{O}_{10}(\mathrm{OH})_{2}, \square=\right.$ defect site) as hydrous magnesium silicates, and forsterite $\left(\mathrm{Mg}_{2} \mathrm{SiO}_{4}\right)$ and an intermediate species between forsterite and enstatite $\left(\mathrm{MgSiO}_{3}\right)$ as anhydrous ones [19]. The surface magnesium silicates of wet-kneaded $\mathrm{SiO}_{2}-\mathrm{MgO}$ attain the balanced acid-base and redox properties with altered $\mathrm{Si}^{4+}-\mathrm{O}^{2-}$ and $\mathrm{Mg}^{2+}-\mathrm{O}^{2-}$ sites and, correspondingly, show its greater activity in the Lebedev process.

Due to the structural complexity of wet-kneaded $\mathrm{SiO}_{2}-\mathrm{MgO}$, the role of magnesium silicate on the Lebedev process has not been clarified yet [6]. Moreover, the characterization of wet-kneaded $\mathrm{SiO}_{2}-\mathrm{MgO}$ is challenging because cross-deposition only occurs on precursor surfaces, forming only a few layers of mixed-phase magnesium silicates. For instance, Janssens et al. reported that surface silanol groups in $\mathrm{SiO}_{2}$ are responsible for the acidic nature and dehydration activity [20]. Chung et al. reported that amorphous magnesium 
silicates are responsible for promoting ethanol dehydration to ethylene and layered $\mathrm{Mg}-\mathrm{Si}$ promotes butadiene formation [19]. In addition, Ochoa et al. observed that the formation of forsterite $\left(\mathrm{Mg}_{2} \mathrm{SiO}_{4}\right)$ by the sol-gel method had the strongest acidity among the series of sol-gel $\mathrm{SiO}_{2}-\mathrm{MgO}$ catalysts, which is detrimental to butadiene selectivity, while favors ethanol dehydration to ethylene [21].

Here, we aim to understand the individual role of magnesium silicate in the wetkneaded $\mathrm{SiO}_{2}-\mathrm{MgO}$ catalyst in the Lebedev process. Varying the calcination temperature, a series of catalysts was prepared, and various characterization were used to study the nature and amount of magnesium silicates, which are largely influenced by thermal treatment. The catalytic performance of the prepared catalysts was evaluated at different ethanol feed rates for proper comparison. We expect that our results may enable further optimization of the wet-kneaded $\mathrm{SiO}_{2}-\mathrm{MgO}$ catalyst and the ethanol-to-butadiene process.

\section{Materials and Methods}

\subsection{Materials}

Tetraethyl orthosilicate ( $\geq 99.0 \%$, Sigma-Aldrich, Steinheim, Germany), ammonium hydroxide (99.99\%, $25 \% \mathrm{NH}_{3}$, Alfa Aesar, Lancashire, UK), ethanol absolute ( $\geq 99.8 \%$, Fisher Scientific, Fair Lawn, NJ, USA), magnesium nitrate hexahydrate ( $\geq 99.0 \%$, SigmaAldrich, Steinheim, Germany), and sodium hydroxide ( $\geq 97.0 \%$, Sigma-Aldrich, Steinheim, Germany) were used as received without further purification.

\subsection{Catalyst Preparation}

The wet-kneaded $\mathrm{SiO}_{2}-\mathrm{MgO}$ catalyst was prepared from $\mathrm{SiO}_{2}$ and $\mathrm{Mg}(\mathrm{OH})_{2}$ precursors according to a published procedure [19]. The Stöber $\mathrm{SiO}_{2}$ was prepared by hydrolysis of tetraethyl orthosilicate in ethanol/ammonium hydroxide solution. After $15 \mathrm{~h}$ of aging, the solid $\mathrm{SiO}_{2}$ nanoparticles were obtained using a rotary evaporator at reduced pressure. The $\mathrm{Mg}(\mathrm{OH})_{2}$ was synthesized adding $0.4 \mathrm{M} \mathrm{NaOH}$ aqueous solution dropwise to $0.2 \mathrm{M}$ $\mathrm{Mg}\left(\mathrm{NO}_{3}\right)_{2}$ aqueous solution until the $\mathrm{pH}$ reached 12. The precipitated $\mathrm{Mg}(\mathrm{OH})_{2}$ particles were separated by centrifugation and washed multiple times with deionized (DI) water. The $\mathrm{SiO}_{2}$ and $\mathrm{Mg}(\mathrm{OH})_{2}$ precursors were dried at $120^{\circ} \mathrm{C}$ overnight. The precursors were wet-kneaded in DI water at room temperature for $4 \mathrm{~h}$. The resultant solid was recovered by centrifugation and dried at $120^{\circ} \mathrm{C}$ overnight. The sample is named WK-dried. The WK-dried sample was then finally thermally treated at different temperatures from 500 to $900{ }^{\circ} \mathrm{C}$ for $5 \mathrm{~h}$ and denoted with the calcination temperature.

\subsection{Characterization}

Scanning electron microscopy (SEM) images of wet-kneading precursors were taken at FEI Teneo VS microscope (FEI Company, Hillsboro, OR, USA). The electron was accelerated at $5 \mathrm{kV}$, and the images were acquired at around $2 \mathrm{~mm}$ working distance.

Powder X-ray diffraction (PXRD) patterns of the materials were recorded on a Bruker D8 Advance X-ray diffractometer (Bruker, Billerica, MA, USA) equipped with a LynxEye position-sensitive detector in $1 \mathrm{D}$ mode. The measurements were acquired by using monochromatic $\mathrm{Cu}-\mathrm{K} \alpha(\lambda=1.5418 \AA)$ radiation operated at $40.0 \mathrm{kV}$. The scan ranged from $2 \theta=5$ to $80^{\circ}$ with a step size of $0.021^{\circ}$ and a scan speed of $1.0 \mathrm{~s}$ per step. The crystalline phases were identified with the help of the PDF-4+ (2019) crystal database. The crystallite size of the catalysts were calculated using the Scherrer equation with a shape factor of 0.89 and an instrument width of 0.05 .

The analysis of textural properties was achieved by nitrogen adsorption at $-196{ }^{\circ} \mathrm{C}$ using Micromeritics ASAP 2420 high-throughput analysis system. Prior to the measurement, the samples were outgassed at $200{ }^{\circ} \mathrm{C}$ under vacuum for $8 \mathrm{~h}$. Specific surface areas were estimated according to the Brunauer-Emmett-Teller (BET) method in the relative pressure range $\left(\mathrm{p} / \mathrm{p}_{0}\right)$ of $0.05-0.95$. The pore size distribution was analyzed by using the Barrett-Joyner-Halenda (BJH) method applied to the desorption branch. 
One-dimensional (1D) ${ }^{1} \mathrm{H}$ spin-echo (SE), ${ }^{29} \mathrm{Si}$ direct excitation (DE), ${ }^{1} \mathrm{H}-{ }^{29} \mathrm{Si}$ crosspolarization (CP), and two-dimensional (2D) ${ }^{1} \mathrm{H}-{ }^{29} \mathrm{Si}$ heteronuclear chemical shift correlation (HETCOR) magic angle spinning (MAS) solid-state nuclear magnetic resonance (NMR) experiments were recorded on a Bruker AVANCE III spectrometer (Bruker BioSpin, Rheinstetten, Germany) operating at a ${ }^{1} \mathrm{H}$ Larmor frequency of $400 \mathrm{MHz}$. One-dimensional and two-dimensional NMR spectra (manufacturer, city, (state or province), country) were recorded using a $4 \mathrm{~mm}$ Bruker triple-resonance and a double-resonance MAS probe, respectively. Dry nitrogen gas was utilized for sample spinning at $12 \mathrm{kHz}$. For ${ }^{1} \mathrm{H}$ SE MAS NMR, a $50 \mathrm{kHz} \pi / 2$ radio frequency (RF) pulse was used, followed by $\pi$ pulse for refocusing, and accumulated for 64 scans. For $1 \mathrm{D}^{29} \mathrm{Si} \mathrm{DE}$, the spectra were recorded using $125 \mathrm{kHz}$ $\pi / 2$ pulse with a long recycle delay of $20 \mathrm{~s}$ for complete relaxation of ${ }^{29} \mathrm{Si}$ nuclei. For ${ }^{1} \mathrm{H}_{-}{ }^{29} \mathrm{Si} \mathrm{CP}$, the spectra were recorded using a $4 \mathrm{~s}$ recycle delay, $20 \mathrm{~ms}$ acquisition time, and accumulation of 22,528 scans. Cross-polarization was achieved using a $85 \mathrm{kHz}{ }^{29} \mathrm{Si}$ field and $38 \mathrm{kHz} 70-100 \%$ ramped ${ }^{1} \mathrm{H}$ field for $3 \mathrm{~ms}$. For $1 \mathrm{D}$ NMR, the ${ }^{1} \mathrm{H}$ and ${ }^{29} \mathrm{Si}$ spectra were processed using 40 and $50 \mathrm{~Hz}$ line-broadening, respectively. The 2D frequency-switched Lee-Goldberg ${ }^{1} \mathrm{H}_{-}{ }^{29} \mathrm{Si}$ HETCOR spectra were acquired with a $12 \mathrm{kHz}$ MAS frequency [22]. The pulse sequence started with a proton pulse, followed by a train of frequency and phase-switched LG pulses (t1 evolution period), and the ramped amplitude $\mathrm{CP}$ to ${ }^{29} \mathrm{Si}$. During the $\mathrm{CP}$ step, ${ }^{1} \mathrm{H} \mathrm{CP}$ spin lock pulses centered at $38 \mathrm{kHz}$ were linearly ramped from 75 to $100 \%$ and the ${ }^{29} \mathrm{Si}$ RF field was matched to obtain an optimal signal. The CP contact time was $3 \mathrm{~ms}$. During the acquisition (t2), the protons were decoupled using a SPINAL-64 sequence. In 2D, linear prediction was used to double the points in the indirect dimension and the exponential multiply window function was applied to both time dimensions. All spectra were referenced to hexamethyl cyclosilane.

Fourier-transform infrared (FTIR) spectra (Thermo Fisher Scientific, Waltham, MA, USA) for pyridine-adsorbed catalysts were collected using a Nicolet 6700 instrument using deuterated triglycine sulfate as the detector with a resolution of $4 \mathrm{~cm}^{-1}$ and 64 scans. The self-supported catalyst pellets (ca. $50 \mathrm{mg}$ of catalyst) were prepared by using a pelletizer with 5 ton pressure. The degassing and IR measurements of the pellet was performed under vacuum using a customized glass setup connected to a Pfeiffer HiCUBE High Vacuum system. The pellet was heated to $90^{\circ} \mathrm{C}$ for $1 \mathrm{~h}$ and to $400^{\circ} \mathrm{C}$ for $3 \mathrm{~h}$, with a heating ramp of $10^{\circ} \mathrm{C} / \mathrm{min}$. After cooling down to room temperature, pyridine vapor was introduced to the pellet for $20 \mathrm{~min}$ and the glass chamber was evacuated for $30 \mathrm{~min}$ to remove physisorbed pyridine. The pellets were heated to $150{ }^{\circ} \mathrm{C}$ for $17 \mathrm{~min}$ under vacuum and then IR spectra were collected.

Temperature-programed desorption of ammonia $\left(\mathrm{NH}_{3}-\mathrm{TPD}\right)$ and carbon dioxide $\left(\mathrm{CO}_{2}-\mathrm{TPD}\right)$ were performed on a Micrometrics ASAP 2920 unit (Micromeritics, Norcross, GA, USA). First, the sample (ca. $100 \mathrm{mg})$ in a quartz reactor was heated $\left(10^{\circ} \mathrm{C} / \mathrm{min}\right)$ in He flow for drying at $350{ }^{\circ} \mathrm{C}$ for $30 \mathrm{~min}$. Subsequently, for $\mathrm{NH}_{3}-\mathrm{TPD}$, the sample was cooled down to $40{ }^{\circ} \mathrm{C}$ and the flow was switched to $\mathrm{NH}_{3}$ (10 vol.\% in He) for $15 \mathrm{~min}$. For $\mathrm{CO}_{2}-\mathrm{TPD}$, the sample was cooled down to $50{ }^{\circ} \mathrm{C}$, and pure $\mathrm{CO}_{2}$, which was previously passed through moisture filter, was flown for $15 \mathrm{~min}$. Then, the flow was switch to He and maintained at $40{ }^{\circ} \mathrm{C}$ for $\mathrm{NH}_{3}\left(50{ }^{\circ} \mathrm{C}\right.$ for $\left.\mathrm{CO}_{2}\right)$ for $15 \mathrm{~min}$ to remove physisorbed species on the catalyst surface. Finally, the sample was heated to $500{ }^{\circ} \mathrm{C}$ with a ramping rate of $5{ }^{\circ} \mathrm{C} / \mathrm{min}$ (to $700^{\circ} \mathrm{C}$ with the rate of $10^{\circ} \mathrm{C} / \mathrm{min}$ for $\mathrm{CO}_{2}$ ) under $\mathrm{He}$, and the desorption of $\mathrm{NH}_{3}$ and $\mathrm{CO}_{2}$ was detected by using a thermal conductivity detector (TCD) and a mass spectrometry detector. The total amount of the adsorbed species was quantified from the preliminary calibrated Cirrus 2 mass spectrometer (MKS Spectra Product, Andover, MA, USA) using $\mathrm{m} / \mathrm{z}=16$ and 28 signals for $\mathrm{NH}_{3}$ and $\mathrm{CO}_{2}$, respectively.

\subsection{Activity Test}

Catalytic experiments were carried out in a 4-channel Flowrence XD high-throughput reactor system (Avantium, Amsterdam, The Netherlands). The reaction tests were carried out at $425{ }^{\circ} \mathrm{C}$ and ambient pressure. The catalyst bed was diluted with silicon carbide 
(SiC) to decrease the effect of axial dispersion and to improve heat conduction in the bed. Typically, $50 \mu \mathrm{L}$ of catalyst was mixed with $200 \mu \mathrm{L}$ of SiC (grit 46) and placed in a quartz tube with an internal diameter of $2.3 \mathrm{~mm}$. A high-performance liquid chromatography pump was used to feed liquid ethanol to the reactor system, and the liquid-hourly space velocity (LHSV, liquid flow volume per hour and per catalyst volume) varied from 0.5 to $1.5 \mathrm{~h}^{-1}$ in nitrogen as a carrier gas. The reaction products were analyzed by gas chromatography (GC) in an Agilent 7890B with three detectors: two flame ionization detectors (FIDs) and one TCD. The TCD channel had a PoraPLOT Q GC column as a backflush column; a Hayesep $\mathrm{Q}$ column for separation of $\mathrm{CO}_{2}$; and a Molsieve as an analytical column for the separation of $\mathrm{He}, \mathrm{H}_{2}, \mathrm{~N}_{2}, \mathrm{CH}_{4}$, and $\mathrm{CO}$. All other compounds (water, hydrocarbons, and oxygenates) were backflushed. The FID was equipped with a $10 \mathrm{~m}$ precolumn with a wax stationary phase. The separation of $C_{1}-C_{5}$ hydrocarbons was carried out on a $30 \mathrm{~m}$ Gaspro stationary phase. The separation of ethanol, acetaldehyde, and the rest of the oxygenates was carried out on a $30 \mathrm{~m}$ wax stationary phase.

The conversion of ethanol $(X)$ and product selectivities $\left(S_{i}\right)$ were calculated based on the following formulas:

$$
\begin{aligned}
& X=\frac{C_{E_{t O H}}-C_{E_{\text {EtOH }}}}{C_{E_{\text {otOH }}}} \times 100 \\
& S_{i}=\frac{i \times C_{i}}{C_{E_{\text {tOH }}}-C_{E_{\text {EtOH }}}} \times 100
\end{aligned}
$$

where $\mathrm{C}_{\mathrm{EtOH}_{\text {in }}}$ and $\mathrm{C}_{\mathrm{EtOH}_{\text {out }}}$ are the concentrations determined by GC analysis of ethanol in the blank and in the reactor.

\section{Results and Discussion}

\subsection{Effect of Thermal Treatment on Wet-Kneaded $\mathrm{SiO}_{2}-\mathrm{MgO}$ Catalyst}

The size and morphology of the precursors $\left(\mathrm{SiO}_{2}\right.$ and $\left.\mathrm{Mg}(\mathrm{OH})_{2}\right)$ heavily influence the physicochemical properties of wet-kneaded $\mathrm{SiO}_{2}-\mathrm{MgO}$ catalysts and, correspondingly, the catalytic activity of the Lebedev process $[19,23]$. In this study, we utilized the best precursors based on our previous result [19] to induce an optimal intimate contact, which are spherical $\mathrm{SiO}_{2}$ particles of $45 \mathrm{~nm}$ in diameter and platelet-like hexagonal $\mathrm{Mg}(\mathrm{OH})_{2}$ prisms of around 135 and $25 \mathrm{~nm}$ in length and height, respectively. The SEM images of the catalyst precursors can be found in Figure S1.

Figure $1 \mathrm{a}$ shows the $\mathrm{X}$-ray diffraction patterns of the prepared wet-kneaded $\mathrm{SiO}_{2}-\mathrm{MgO}$ catalysts calcined at different temperatures. A typical hexagonal $\mathrm{Mg}(\mathrm{OH})_{2}$ brucite phase with P-3m1 space group symmetry (PDF\# 00-044-1482) was observed in the WK-dried sample (Figure 1a). After calcination at $500{ }^{\circ} \mathrm{C}$, the brucite (001) phase dehydroxylated to form a MgO cubic periclase (111) phase (Fm-3m, PDF\# 04-010-4039) [24], either by the migration of $\mathrm{Mg}^{2+}$ [25] or by the oxygen layers slip [26]. Crystal-size analysis using the Scherrer equation shows $21 \mathrm{~nm}$ size brucite crystals disappearing and forming new and smaller $(8.5 \mathrm{~nm})$ periclase crystals (Figure $1 \mathrm{~b}$ and Table 1$)$. Once the periclase phase formed, these crystallites gradually agglomerated with increasing calcination temperature.

Notably, for the calcined catalysts at higher temperatures (WK-800 and WK-900), the development of crystalline magnesium silicates, more specifically, orthorhombic $\mathrm{Mg}_{2} \mathrm{SiO}_{4}$ forsterite (Pbnm, PDF\# 01-175-6661) was observed. The characteristic diffraction pattern of forsterite became more intense for the WK-900 catalyst. It is worth noting that other anhydrous magnesium silicates such as enstatite $\left(\mathrm{MgSiO}_{3}\right)$ and its polymorphs were not observed. In addition, all samples showed a broad contribution in the region of 20-30 20. This strongly suggests that the wet-kneaded $\mathrm{SiO}_{2}-\mathrm{MgO}$ catalysts still preserve an amorphous $\mathrm{SiO}_{2}$ phase in the inner core of spherical $\mathrm{SiO}_{2}$ particles, i.e., wet-kneading modifies only the precursor surfaces. 
a

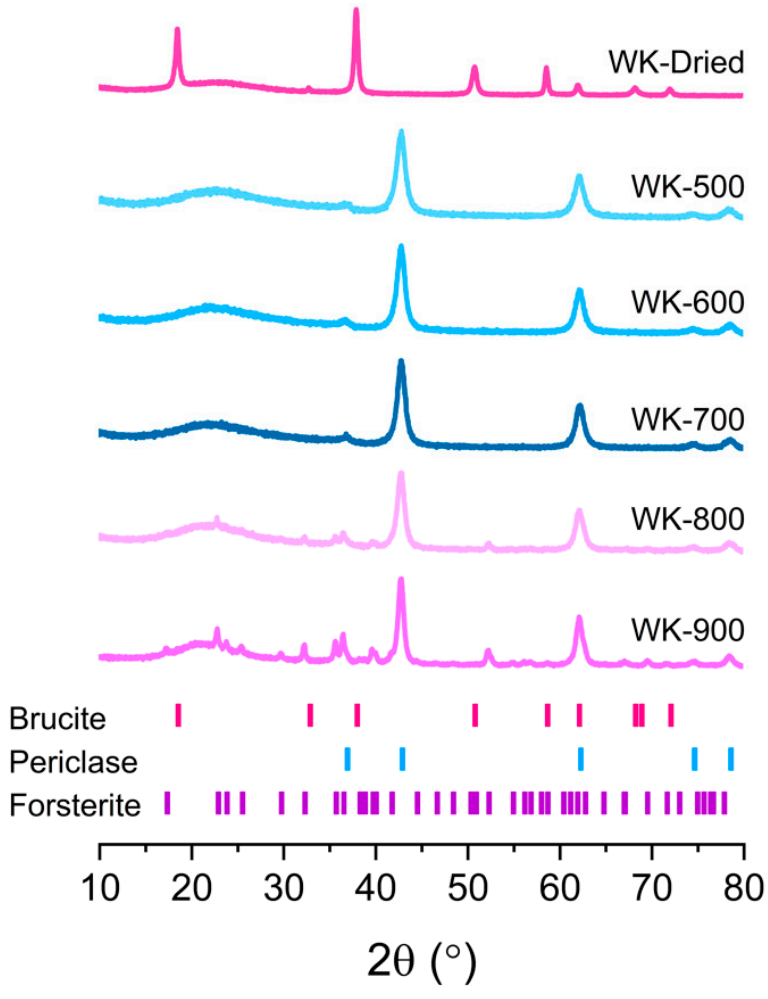

b

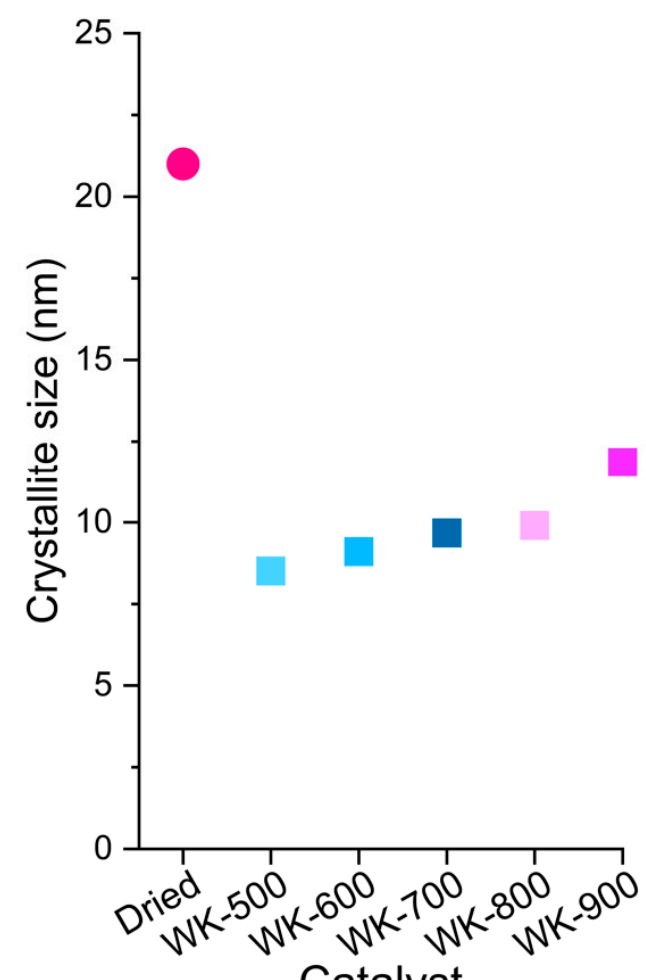

Figure 1. (a) Powder X-ray diffraction (PXRD) patterns of wet-kneaded $\mathrm{SiO}_{2}-\mathrm{MgO}$ catalysts prepared at different calcination temperatures. The diffraction peaks for brucite $\left(\mathrm{Mg}(\mathrm{OH})_{2}\right)$, periclase $(\mathrm{MgO})$, and forsterite $\left(\mathrm{Mg}_{2} \mathrm{SiO}_{4}\right)$ are denoted at the bottom of the figure. (b) The crystallite sizes of WK catalysts, calculated using the Scherrer equation using brucite (001) and periclase (111) planes for the WK-dried and WK-calcined samples, respectively.

Table 1. Nitrogen physisorption results and calculated crystallite sizes of wet-kneaded $\mathrm{SiO}_{2}-$ MgO catalysts.

\begin{tabular}{|c|c|c|c|c|c|c|}
\hline Catalyst & $\begin{array}{l}\text { Crystallite } \\
\text { Size }^{1} \\
(\mathrm{~nm})\end{array}$ & $\begin{array}{c}\text { BET Surface } \\
\text { Area }{ }^{2} \\
\left(\mathrm{~m}^{2} / \mathrm{g}\right)\end{array}$ & $\begin{array}{c}\text { Microporous } \\
\text { Area } \\
\left(\mathrm{m}^{2} / \mathrm{g}\right)\end{array}$ & $\begin{array}{c}\text { Total Surface } \\
\text { Area } \\
\left(\mathrm{m}^{2} / \mathrm{g}\right)\end{array}$ & $\begin{array}{l}\text { Micropore } \\
\text { Volume } \\
\left(\mathrm{cm}^{3} / \mathrm{g}\right)\end{array}$ & $\begin{array}{c}\text { Total Pore } \\
\text { Volume } \\
\left(\mathrm{cm}^{3} / \mathrm{g}\right)\end{array}$ \\
\hline WK-Dried ${ }^{3}$ & 21 & 143 & 22 & 165 & 0.04 & 0.37 \\
\hline WK-500 & 8.5 & 191 & 27 & 218 & 0.06 & 0.44 \\
\hline WK-600 & 9.1 & 171 & 23 & 194 & 0.06 & 0.43 \\
\hline WK-700 & 9.6 & 171 & 28 & 199 & 0.05 & 0.44 \\
\hline WK-800 & 9.9 & 135 & 19 & 154 & 0.04 & 0.38 \\
\hline WK-900 & 11.9 & 94 & 17 & 111 & 0.03 & 0.30 \\
\hline
\end{tabular}

${ }^{1}$ Crystallite size was calculated from PXRD results using the Scherrer equation. The crystallite size of WK-dried was calculated using the (001) and (111) planes of brucite and periclase, respectively. ${ }^{2}$ The total pore volume was estimated from a single point adsorption measurement at $\mathrm{p} / \mathrm{p}_{0}=0.95$ for pore sizes below $50 \mathrm{~nm}$, disregarding macropores. ${ }^{3}$ Nitrogen adsorption for WK-dried samples was measured after degassing at $120^{\circ} \mathrm{C}$.

The textural properties of the catalysts were investigated by $\mathrm{N}_{2}$ adsorption at $-196^{\circ} \mathrm{C}$. The wet-kneaded $\mathrm{SiO}_{2}-\mathrm{MgO}$ catalysts displayed type IV adsorption isotherms, with an H3 loop characteristic of layered materials containing wide mesopores (Figure 2). Notably, variation in the calcination temperature shows a volcano-shaped trend of the BET surface area of the samples, showing a maximum with the WK-500 catalyst. Compared to WKdried, the surface area of WK-500 increased by about 33\%. The dehydration of brucite crystals occurred while the water molecules escaped from the crystalline lattices. Owing to the inhomogeneous dehydration of brucite $[25,26]$, pores of sizes around $3.5 \mathrm{~nm}$ were generated after calcination at $500{ }^{\circ} \mathrm{C}$ (Figure S2). The surface area and pore volume of the catalysts decreased significantly at higher calcination temperatures (Table 1). WK-800 and -900 exhibited type IVb isotherms [27], suggesting not only small pores, which were formed by brucite dehydration, but also that the one end of the interparticle pores (ca. $10 \mathrm{~nm}$ ) are 
partially blocked by calcination at $800-900{ }^{\circ} \mathrm{C}$, forming forsterite on the catalyst surface (Figure S2).

a

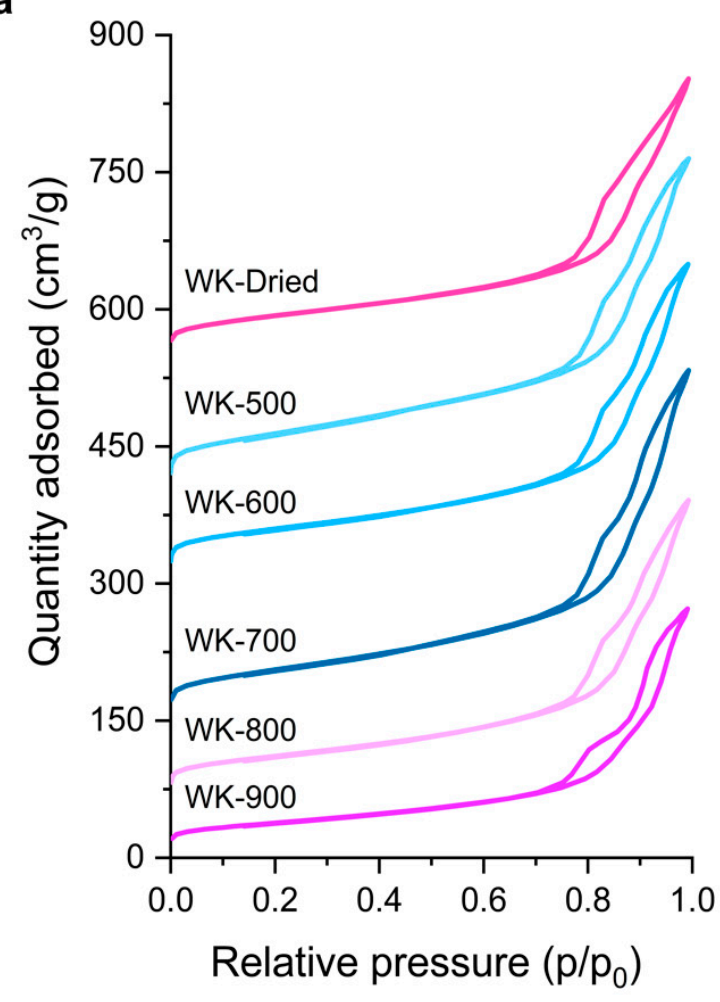

b

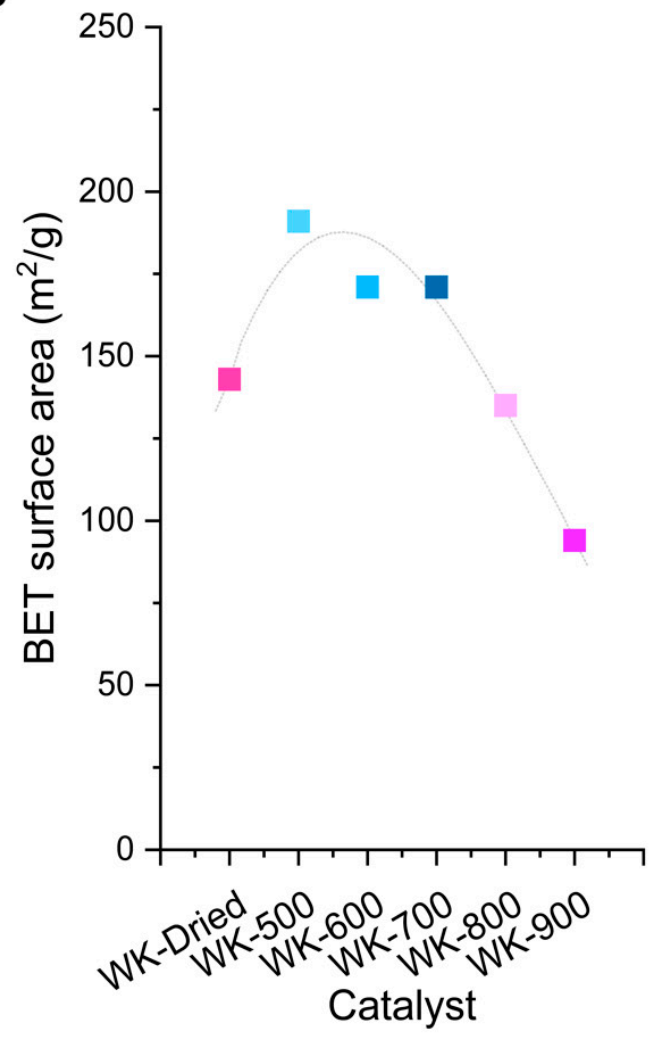

Figure 2. Nitrogen adsorption-desorption isotherms (a) and Brunauer-Emmett-Teller (BET) surface area (b) of the prepared wet-kneaded $\mathrm{SiO}_{2}-\mathrm{MgO}$ catalysts. The isotherms are offset for clarity.

Further insights into the structure of the catalysts were investigated in detail by solidstate NMR spectroscopy. This tool was proven to play a pivotal role in the understanding of magnesium silicates formed by wet-kneading $[19,23]$. Although ${ }^{1} \mathrm{H}$ NMR could provide structural insights of the hydroxyl groups on $\mathrm{SiO}_{2}$ [28], $\mathrm{MgO}$ [29], and pure magnesium silicates [30-32], ${ }^{1} \mathrm{H}$ spectra of wet-kneaded $\mathrm{SiO}_{2}-\mathrm{MgO}$ catalysts has not been reported so far, probably due to the massive signals from adsorbed water and the complexity of the various proton signals. Here, we provide the ${ }^{1} \mathrm{H}$ MAS NMR spectra of the wet-kneaded $\mathrm{SiO}_{2}-\mathrm{MgO}$ catalysts calcined at different temperatures (Figure 3). For a better understanding, the spectra of the individual $\mathrm{SiO}_{2}$ and $\mathrm{MgO}$ are also summarized in Figure S3. Although we could not completely average the strong dipolar coupling of water molecules, (at least) two broad resonances at around 4 and $5 \mathrm{ppm}$ were observed, showing the heterogeneity of adsorption sites for water on the catalysts. It is known that the chemical shift in adsorbed water on the catalyst surface is influenced by the hydrogen bond strength between water and the surface hydroxyl groups [28,29]. The chemical shift and intensity of the resonance of physisorbed water can also be affected by the local electric field from surface polarity $[30,33]$. Notably, WK-800 still has a considerable amount of water on the surface, suggesting its hydrous features. On the contrary, WK-900 showed its anhydrous features: the resonance at around $5 \mathrm{ppm}$ disappeared, and only a small amount of surface water was observed at $3.7 \mathrm{ppm}$ due to the formation of nonpolar and rigid $\mathrm{O}-\mathrm{Mg}-\mathrm{O}$ layers of forsterite [34,35], with a small contribution of $\mathrm{Q} 4$ siloxane groups on the $\mathrm{SiO}_{2}$ [28]. 


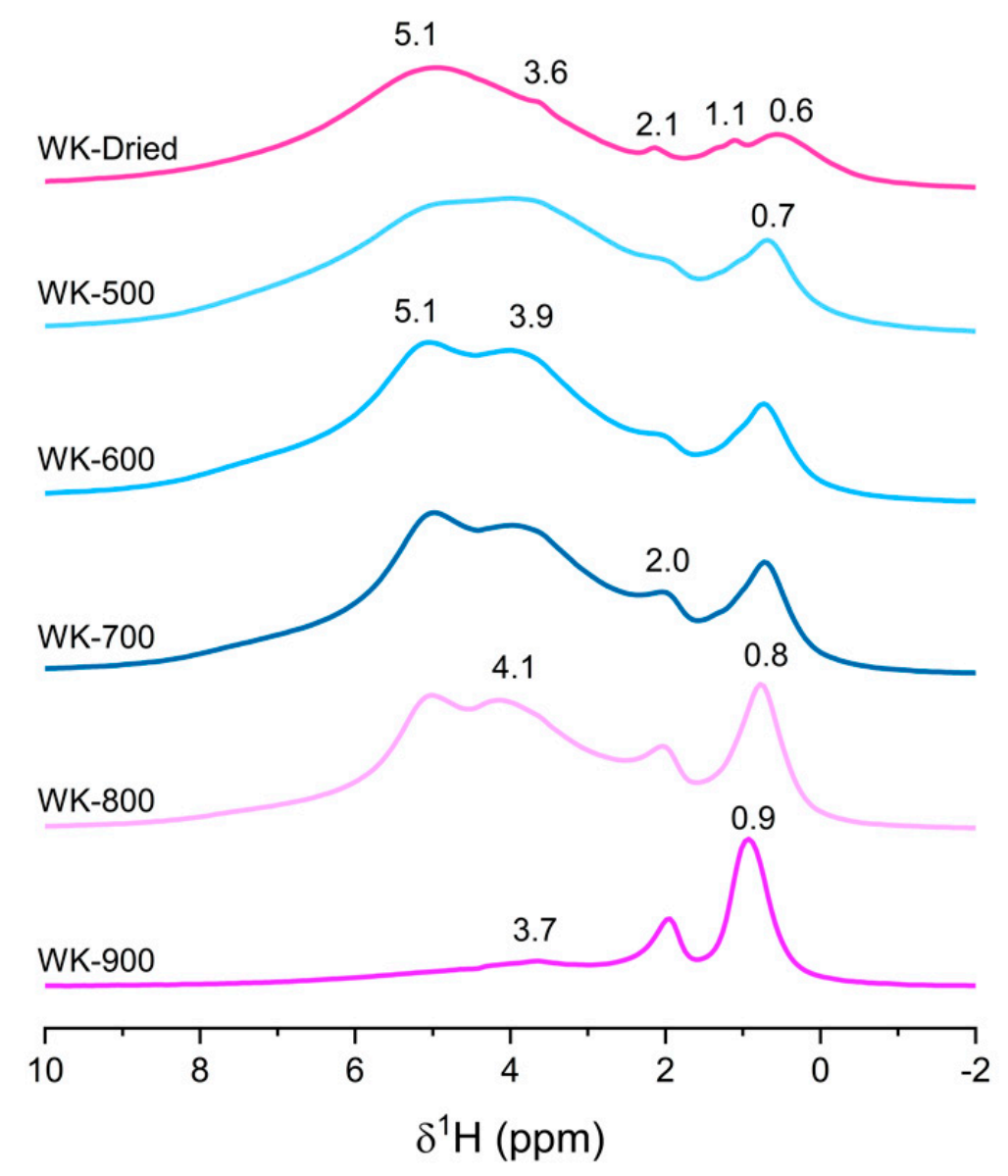

Figure 3. ${ }^{1} \mathrm{H}$ spin-echo magic angle spinning (MAS) NMR spectra of the wet-kneaded $\mathrm{SiO}_{2}-\mathrm{MgO}$ catalysts with varying calcination temperatures. The intensities arbitrarily scaled to the maximum peak height for clarity.

This leaves three signals at around 2.0,1.1, and $0.6 \mathrm{ppm}$ to be assigned. The regions from 0 to 2 ppm can provide insights into the actual structural hydroxyl groups but it is not straightforward due to extensive overlaps. For example, all pure precursors exhibit features at around 2 ppm (Figure S3). Dumas et al. indicated that synthetic talc displays a ${ }^{1} \mathrm{H}$ resonance of silanol on lateral sheet edges at $1.8 \mathrm{ppm}$ [30], while Poirer et al. assigned this peak to residual sodium acetate during the synthesis [36]. For WK-dried and WK-500, the ${ }^{1} \mathrm{H}$ resonance at around $0.6 \mathrm{ppm}$ is one of the predominant resonances with small features of $1.1 \mathrm{ppm}$. From its asymmetric features, it is expected to be overlapped with several features of hydrous magnesium silicates [19], as well as MgO (Figure S3). Interestingly, upon calcination at higher temperature, the signal at $0.6 \mathrm{ppm}$ shifted downfield by 0.3 ppm and became more resolved, suggesting that isolated hydroxyl groups become more structurally ordered. Because of the complexity of these spectra, assignment of the remaining contributions will be discussed with the $2 \mathrm{D}^{1} \mathrm{H}-{ }^{29} \mathrm{Si}$ HETCOR results below.

The ${ }^{29} \mathrm{Si}$ and ${ }^{1} \mathrm{H}-{ }^{29} \mathrm{Si}$ CP MAS NMR spectra provide additional information on the nature of magnesium silicates on wet-kneaded $\mathrm{SiO}_{2}-\mathrm{MgO}$ catalysts (Figure 4 ). In the ${ }^{29} \mathrm{Si}$ direct excitation (DE) spectra (Figure 4a), the resonance at $-109.8 \mathrm{ppm}$, ascribed to Q4 siloxane groups, is the most intense for all catalysts, suggesting that the inner core of spherical $\mathrm{SiO}_{2}$ is maintained during wet-kneading, in agreement with our XRD results. Compared to pure $\mathrm{SiO}_{2}$ nanoparticles, the ${ }^{29} \mathrm{Si}$ resonances of the catalysts are asymmetrically broadened, especially downfield, showing an alteration of the chemical environment of silicon species by wet-kneading (Table 2). After calcination, a large portion of silicon species at around -100.0 ppm (e.g., the so-called simple silanol groups, $(\mathrm{SiO})_{3}-$ $\mathrm{Si}-\mathrm{OH})$ ) were transformed to magnesium silicates (WK-dried and WK-500 in Figure 4a). A 
broad signal was observed at $-79.0 \mathrm{ppm}$, attributed to a combinations of a structurally illdefined (amorphous) hydrous magnesium silicate (in the region of -85 to $-92 \mathrm{ppm}$ ) $[37,38]$ and intermediate species between forsterite and enstatite ( $-77.6 \mathrm{ppm})$ [39]. In addition, a resonance of poorly crystalline lizardite $(-93.8 \mathrm{ppm})[19,40]$ was clearly observed as the calcination temperature increased. The intensities of ${ }^{29} \mathrm{Si}$ resonances in the region -70 to $-95 \mathrm{ppm}$ increase with calcination temperatures up to $800{ }^{\circ} \mathrm{C}$. For WK-900, the formation of forsterite ( $-61.3 \mathrm{ppm})$ was clearly observed [41], at the expense of the signals of magnesium silicates in the region of -70 to $-100 \mathrm{ppm}$. WK-900 displayed a broaden Q4 resonance despite the highest temperature calcination, probably due to the formation of additional $\mathrm{SiO}_{2}$ phases by the dehydroxylation of the magnesium silicates.
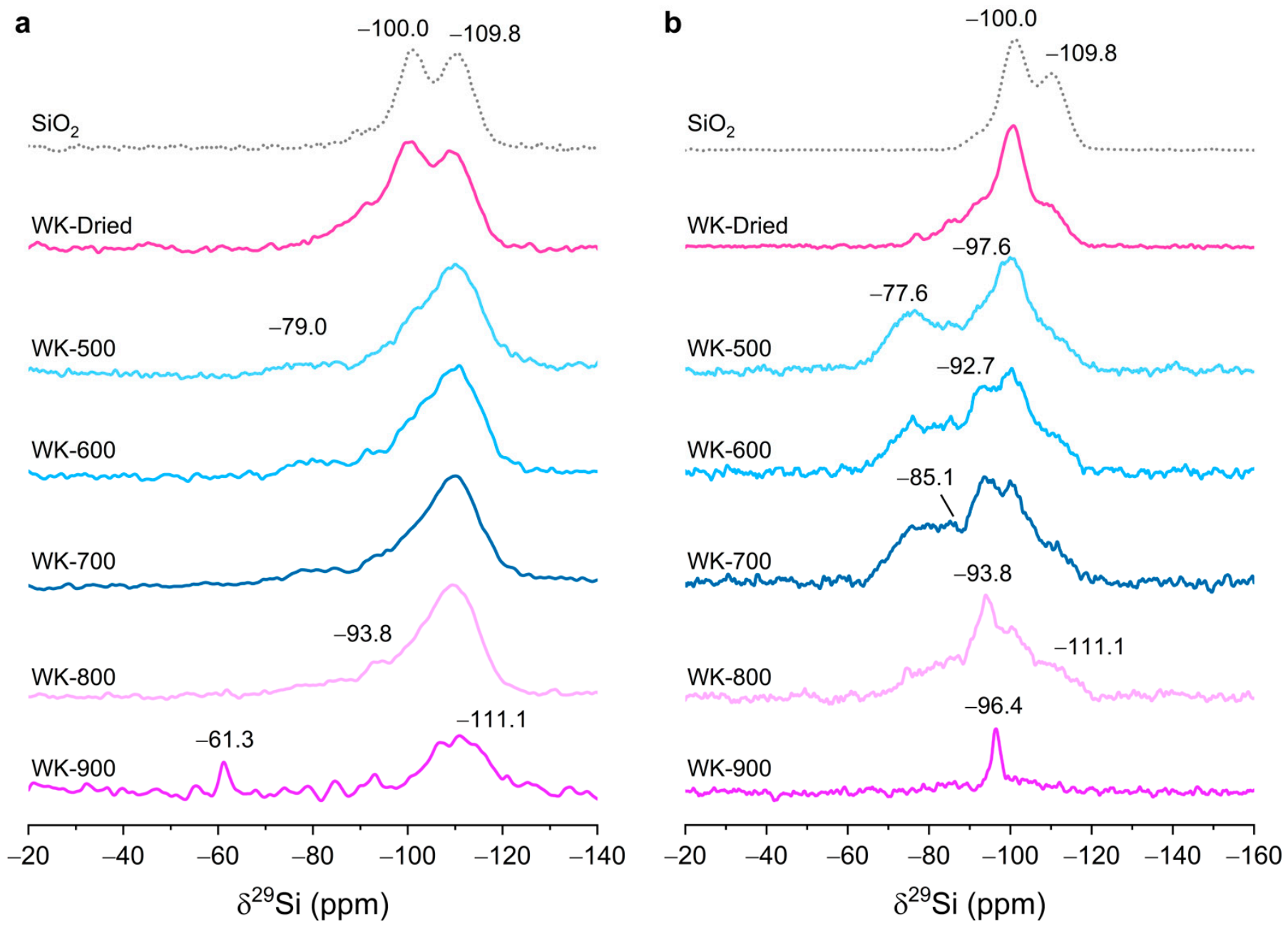

Figure 4. Solid-state ${ }^{29} \mathrm{Si}$ direct excitation (a) and ${ }^{1} \mathrm{H}-{ }^{29} \mathrm{Si}$ cross-polarized MAS NMR spectra (b) of the wet-kneaded $\mathrm{SiO}_{2}-\mathrm{MgO}$ catalysts prepared with varying calcination temperature. The intensities are arbitrarily scaled to the maximum peak height for the clarity. The spectra of pure $\mathrm{SiO}_{2}$ was plotted as dashed line as a reference (scaled to intensity of Q4 in WK-dried). 
Table 2. List of ${ }^{29} \mathrm{Si}$ chemical shift values and assignments for magnesium silicates reported in the literature.

\begin{tabular}{|c|c|c|c|}
\hline $\begin{array}{c}\text { Observed } \\
{ }^{29} \text { Si Chemical Shift } \\
(p p m)\end{array}$ & Assignment & Structure & Literature \\
\hline-109.8 & Silica (Q4) & $\mathrm{Si}-(\mathrm{OSi})_{4}$ & [28] \\
\hline-100.0 & Silica (Q3) & $\mathrm{Si}-(\mathrm{OSi})_{3}(\mathrm{OH})$ & {$[28]$} \\
\hline-97.6 & Talc & $\mathrm{Mg}_{3} \mathrm{Si}_{4} \mathrm{O}_{10}(\mathrm{OH})$ & [43] \\
\hline-96.4 & Stevensite & $\begin{array}{c}\mathrm{Mg}_{\mathrm{x}}\left(\mathrm{Mg}_{3-\mathrm{x}} \square \mathrm{x}\right) \mathrm{Si}_{4} \mathrm{O}_{10}(\mathrm{OH})_{2} \\
(\square=\text { defect site })\end{array}$ & [42] \\
\hline-93.8 & Lizardite & $\left(\mathrm{Mg}_{3} \mathrm{Si}_{2} \mathrm{O}_{5}(\mathrm{OH})_{4}\right)$ & [40] \\
\hline$-85--92$ & $\begin{array}{c}\text { Amorphous hydrous } \\
\text { magnesium silicates }\end{array}$ & 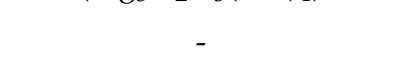 & {$[38,44]$} \\
\hline-82.0 & $\begin{array}{c}\text { Enstatite } \\
\text { Intermediate }\end{array}$ & $\mathrm{MgSiO}_{3}$ & [45] \\
\hline-77.6 & $\begin{array}{l}\text { betweenforsterite and } \\
\text { enstatite }\end{array}$ & $\left(\mathrm{Mg}_{2} \mathrm{SiO}_{4}\right)_{\mathrm{x}}\left(\mathrm{MgSiO}_{3}\right)_{1-\mathrm{x}}$ & [39] \\
\hline-61.3 & Forsterite & $\mathrm{Mg}_{2} \mathrm{SiO}_{4}$ & [46] \\
\hline
\end{tabular}

With ${ }^{1} \mathrm{H}-{ }^{29}$ Si CP MAS experiments, we could obtain more resolved spectra of the wet-kneaded $\mathrm{SiO}_{2}-\mathrm{MgO}$ catalysts (Figure $4 \mathrm{~b}$ ). These CP experiments could selectively enhance surface magnesium silicate species due to more dense protons at the catalyst surface compared to bulk species, either by the physisorbed water or by surface hydroxyl groups. Notably, the ${ }^{29} \mathrm{Si}$ resonances for layered magnesium silicates such as lizardite, stevensite, and talc $\left({ }^{29} \mathrm{Si}=-93.8,-96.4\right.$, and $-97.6 \mathrm{ppm}$, respectively) were greatly enhanced for WK-dried and WK-500, which means a more efficient cross-polarization transfer was evidenced. It should be clearly noted here that the enhanced intensities of $\mathrm{CP}$ experiments largely depend on several factors of polarization transfer from ${ }^{1} \mathrm{H}$ to ${ }^{29} \mathrm{Si}$, such as the proton density around silicon nucleus, the distances between protons and silicon, and the transfer efficiency modulated by the silicon environment (i.e., different relaxation rates). For example, despite $\mathrm{Q} 4$ species being the most abundant in pure $\mathrm{SiO}_{2}$, the signal intensities of the simple silanol groups (Q3 at $-100.0 \mathrm{ppm}$ ) are more enhanced. For WK-500, the signal intensity at $-77.6 \mathrm{ppm}$, which is related to the intermediate species between forsterite and enstatite [39], was significantly enhanced. This suggests that the intermediate species between forsterite and enstatite still preserves structural hydroxyl groups due to the low temperature calcination despite their anhydrous nature; the intermediate species are hydrophilic and surrounded by considerable amounts of physisorbed water molecules. Similarly, amorphous hydrous magnesium silicates (in the region of -85 and $-92 \mathrm{ppm}$ ) seemed to increase upon calcination (for WK-600 and WK-700) due to the transition of hydroxyl groups from ill-defined to (relatively) ordered structures [19]. Further calcination at $800{ }^{\circ} \mathrm{C}$ brought about a sharp resonance at $-93.8 \mathrm{ppm}$, suggesting that the local crystallinity of lizardite increases and that transfer of magnetization from proton to silicon occurs more effectively. WK-800 displayed the broadened Q4 resonance, most probably due to the formation of additional $\mathrm{SiO}_{2}$ phases by the dehydroxylation of the magnesium silicates at high-temperature calcination.

For WK-900, ${ }^{29}$ Si resonance at -61.3 ppm was not observed with the CP experiment because of an absence of structural protons in forsterite. Notably, a new resonance at -96.4 ppm was clearly observed, attributed to a defect site containing talc-like magnesium silicate and stevensite $[19,42]$. Taken together with the ${ }^{29}$ Si DE NMR spectra for WK-900 (Figure 4a), this suggests that the dehydroxylation of structural hydroxyl groups occurring the surface of WK-900 mostly consists of forsterite, while a certain number of defectcontaining stevensites decorate the grain boundary of forsterite. By the CP experiment, the broadened features of Q4 resonance, which was observed for WK-800, was hardly seen for WK-900, indicating that the $\mathrm{SiO}_{2}$ is now fully covered by forsterite and stevensite species. The observed ${ }^{29} \mathrm{Si}$ species by ${ }^{1} \mathrm{H}-{ }^{29} \mathrm{Si}$ CP MAS NMR are summarized in Table S1. 
We used $2 \mathrm{D}^{1} \mathrm{H}-{ }^{29} \mathrm{Si}$ HETCOR NMR to study the correlation between protons and ${ }^{29} \mathrm{Si}$ species for the WK-500, -800, and -900 catalysts (Figure 5). In this 2D NMR experiment, only the ${ }^{29} \mathrm{Si}$ species in close proximity to protons are observed and the intensity of the cross-peaks $\left(\delta^{29} \mathrm{Si}, \delta^{1} \mathrm{H}\right)$ is semiquantitative because the dipolar couplings are inversely proportional to the distance between the nuclei. For WK-500 and WK-800, we observed broad resonances at the pairs of shifts around $(-100.0,5.0) \mathrm{ppm}$ (Figure 4), ascribed to physisorbed water molecules on the surface $\mathrm{Q} 3$ silanol groups. The observed resonance at $2.0 \mathrm{ppm}$ in $1 \mathrm{D}^{1} \mathrm{H}$ NMR experiment (Figure 3) was not observed in the 2D HETCOR experiment, suggesting that the proton is attributed to $\mathrm{Mg}-\mathrm{OH}$ groups either on the surface of $\mathrm{MgO}$ or magnesium silicates, especially for the high-temperature calcined WK900 catalyst.

\section{a}

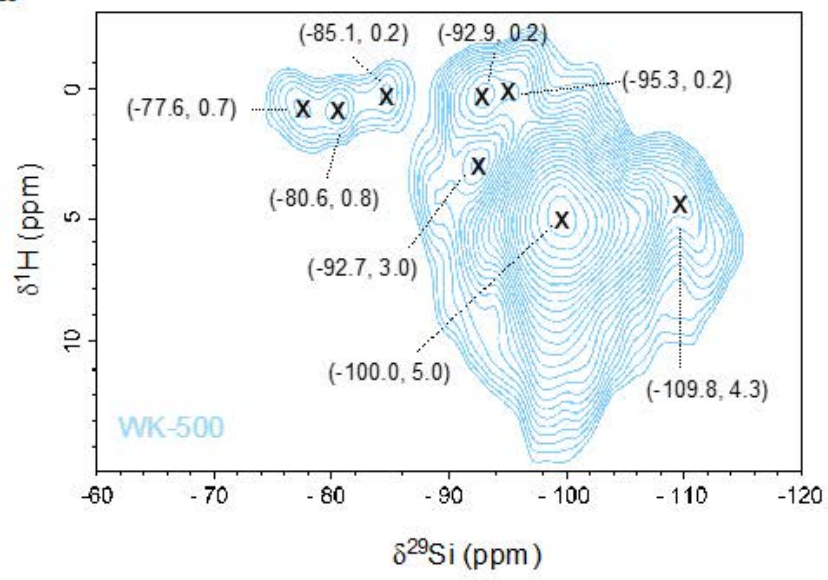

b

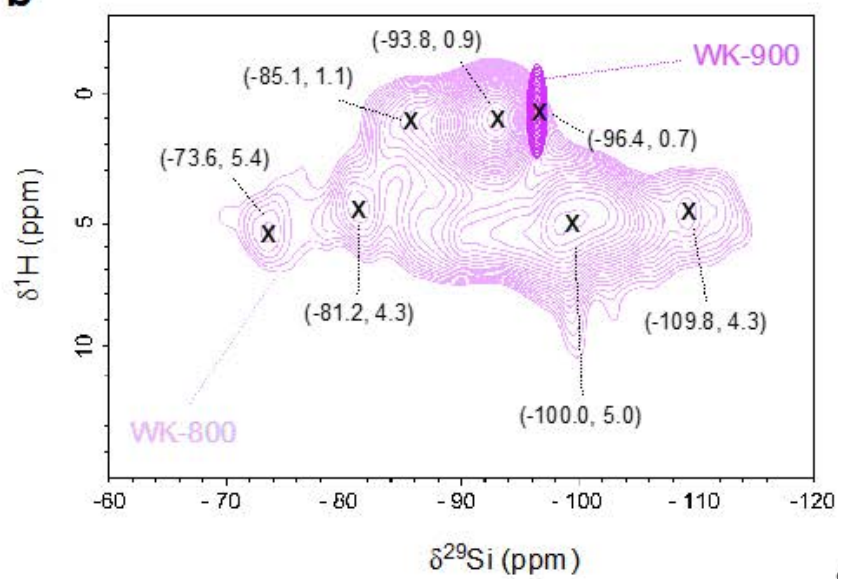

Figure 5. Two-dimensional ${ }^{1} \mathrm{H}-{ }^{29} \mathrm{Si}$ heteronuclear correlation (HETCOR) MAS NMR of (a) WK-500, and (b) WK-800 (light purple) and WK-900 (dark purple).

The presence of magnesium silicates is clearly evidenced in the $2 \mathrm{D}^{1} \mathrm{H}-{ }^{29} \mathrm{Si}$ HETCOR NMR spectra, with a clear correlation signal of structural protons at $\delta^{1} \mathrm{H} \simeq 0.7$. WK-500 in the cross-peaks of the intermediate species between forsterite and enstatite at $(-77.6$, $0.7)$ and $(-80.6,0.8) \mathrm{ppm}$. After calcination at $800^{\circ} \mathrm{C}$, we observed large chemical shifts in $\mathrm{F} 1\left({ }^{1} \mathrm{H}\right)$ dimension to $(-73.6,5.4)$ and $(-81.2,4.3) \mathrm{ppm}$, indicating that the structural protons are released from the surface of the intermediate magnesium silicates and that water is physisorbed on these sites. We speculate that the intermediate species still have oxygen-rich planes at their surfaces because of the considerable signals attributed to the adsorbed water on the surface (Figures 3 and 5). In addition, the amorphous magnesium silicate and lizardite species were found to be thermally stable, displaying a slight shift from $(-84.9,0.2)$ and $(-92.7,0.3)$ to $(-86.5,1.1)$ and $(-92.8,1.0) \mathrm{ppm}$.

Although talc is one of the hydrous magnesium silicates in the wet-kneaded $\mathrm{SiO}_{2}-$ $\mathrm{MgO}$ catalyst [19,47], we could not observe the signal attributed to talc in the 2D HETCOR experiment, which was clearly seen in the $1 \mathrm{D}^{1} \mathrm{H}^{29} \mathrm{Si} \mathrm{CP}$ MAS spectra of WK-dried and WK-500 $\left(\delta^{29} \mathrm{Si}=-97.6 \mathrm{ppm}\right.$ in Figure $\left.4 \mathrm{~b}\right)$. This could be due to the weak proton signals buried under the neighboring massive signals in the HETCOR experiment [48], such as the presence of a considerable amount of water on Q3 silicon species in our case. For WK-900, the resonance of forsterite was not observed in reference to the anhydrous feature, while the actual resonance of stevensite was speculated at $(-96.4,0.7) \mathrm{ppm}$.

In summary, the formation of amorphous anhydrous magnesium silicate and lizardite is promoted by thermal treatment until $800{ }^{\circ} \mathrm{C}$. Further calcination above $800{ }^{\circ} \mathrm{C}$ results in a phase transition at the surface of wet-kneaded $\mathrm{SiO}_{2}-\mathrm{MgO}$ : most of the isolated silanol groups (Q3) react with nearby magnesium species to form forsterite while maintaining a stevensite structure at the edge of the grain boundary. 


\subsection{Catalytic Activity}

First, the catalytic performances of the wet-kneaded samples were compared with a physical mixture of $\mathrm{SiO}_{2}$ and $\mathrm{MgO}$ (Table S2). Notably, the physical mixture catalyst converted ethanol mostly into acetaldehyde ( $77 \%$ selectivity) but almost no butadiene was observed ( $2.4 \%$ selectivity). This indicates that the pristine $\mathrm{SiO}_{2}$ and $\mathrm{MgO}$ have limited catalytic sites for aldol condensation, one of the suggested rate-determining step toward butadiene formation [15]. On the other hand, the wet-kneaded $\mathrm{SiO}_{2}-\mathrm{MgO}$ catalysts showed superior catalytic performance compared to the physical mixture catalyst in terms of ethanol conversion and butadiene selectivity. The magnesium silicates formed by wet-kneading promoted not only aldol condensation but also the sequential steps for butadiene formation.

Figure 6 shows the catalytic activity results of the prepared wet-kneaded $\mathrm{SiO}_{2}-\mathrm{MgO}$ catalysts for the Lebedev ethanol-to-butadiene process. The overall catalytic activities of our wet-kneaded catalysts are in line with previous results of the $\mathrm{SiO}_{2}-\mathrm{MgO}$ system in literature $[19,49,50]$. With increasing calcination temperatures, ethanol conversion decreases due to the less active sites available on the catalyst surface (Figure 6a). Interestingly, the surface-area-normalized activities (specific activities) decrease as the calcination temperature increases to $700{ }^{\circ} \mathrm{C}$ while WK-900 showed the best performance (Figure $6 \mathrm{~b}$ ). This indicates that ethanol conversion is largely influenced not only by the surface area but also by the structural properties of the distinct catalysts. More specifically, the dominant magnesium silicate phases in WK-800 (amorphous magnesium silicates and lizardite) are less active than the combination of forsterite and stevensite (WK-900) in ethanol conversion.

Next, we performed catalytic tests at different ethanol feed rates ( 0.5 to $1.5 \mathrm{~h}^{-1}$ LHSV) to study product distribution with residence time ((Figure 6c, Figure S4 and Table S2). In all cases, ethanol conversion decreased with higher LHSV, meaning that the reaction rate is limited to the number of active sites (surface area) and/or the existence of competitive adsorption of ethanol and the intermediates/products. Indeed, ethanol is converted into ethylene and acetaldehyde over catalytic sites by dehydration and dehydrogenation, respectively, and the negative correlation between acetaldehyde and ethylene shows that the (limited number of) catalytic sites are occupied by those two chemicals in a competitive manner (Figure 6d). Butadiene selectivity, however, is not very sensitive to acetaldehyde although butadiene is formed via acetaldehyde.

a

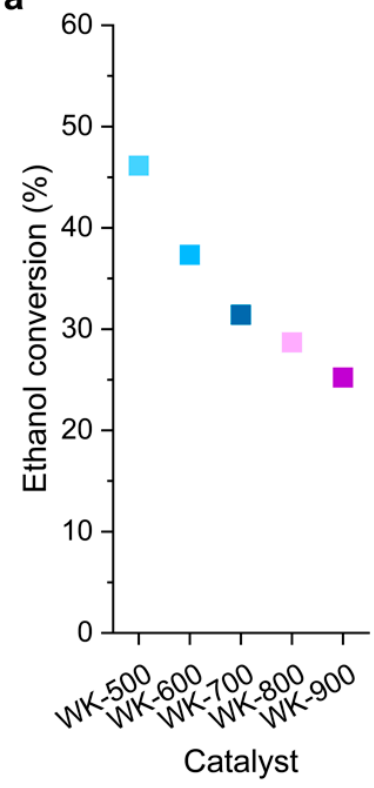

b

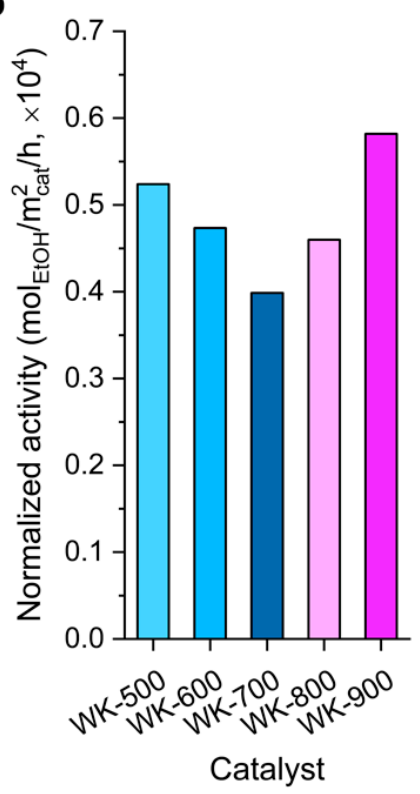

C

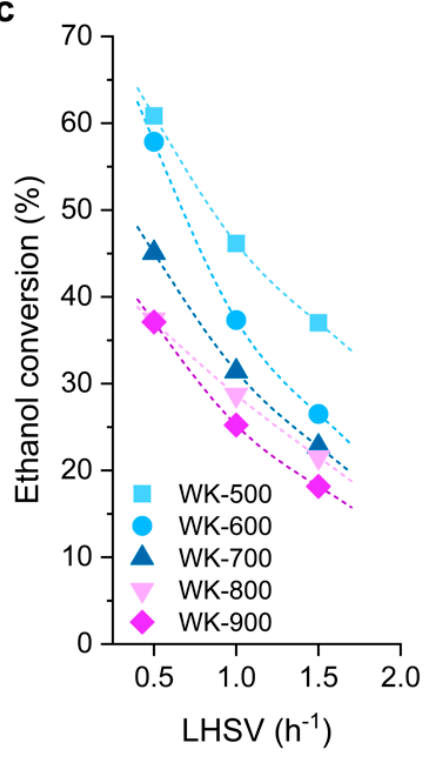

Figure 6. Cont. 

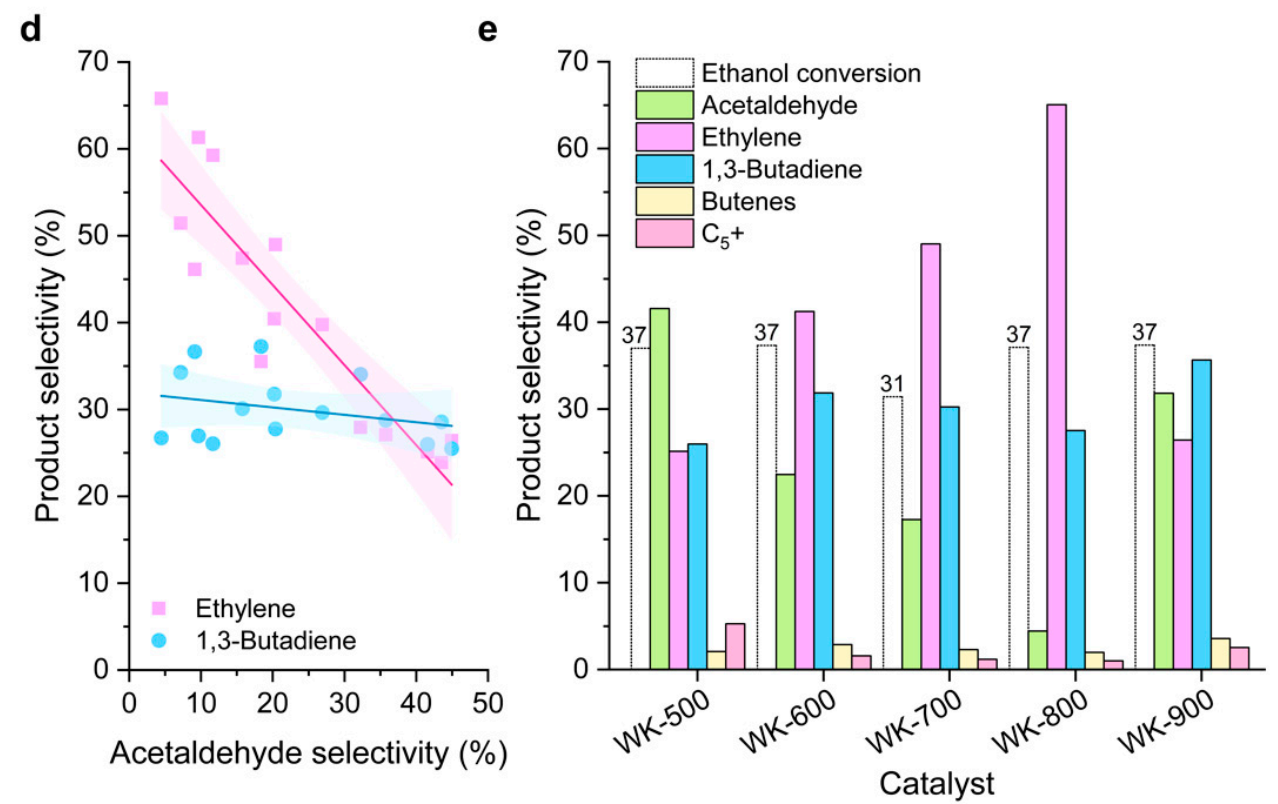

Figure 6. Comparison of (a) the ethanol conversion at $1.0 \mathrm{~h}^{-1}$ liquid-hourly space velocity (LHSV), (b) normalized catalytic activity at $1.0 \mathrm{~h}^{-1} \mathrm{LHSV}$, (c) ethanol conversion with varying LHSV $\left(0.5\right.$ to $\left.1.5 \mathrm{~h}^{-1}\right)$, (d) product selectivity as a function of key intermediate (acetaldehyde) with the $95 \%$ confidence band, and (e) product distribution at the same ethanol conversions for the different catalysts under study.

The product selectivities of the prepared catalysts were compared at the same ethanol conversion levels $(\approx 37 \%$, Figure $6 \mathrm{e})$. With increasing calcination temperature, the acetaldehyde selectivity decreased while ethylene selectivity greatly increased. Taken together with the characterization results, the local crystallinity of the amorphous magnesium silicates and lizardite is relative to the ethylene selectivity; that is, the protons that are strongly bound to the structures of those magnesium silicates promote the ethanol dehydration. Notably, after calcination at $900{ }^{\circ} \mathrm{C}$, ethylene selectivity was greatly reduced to $27.5 \%$. It is worth noting the difference in catalyst surface polarities of WK-800 and WK-900 (Figures 3 and 5). Cavani et al. suggested that water that is generated in situ during the Lebedev process can transform Lewis acid sites into Brønsted acid sites, leading to an increase in ethylene selectivity [21]. In this regard, we propose that the Lewis sites of WK-800 prefers to be converted to Brønsted acid sites by in situ generated water. In addition, the rigid $\mathrm{O}-\mathrm{Mg}-\mathrm{O}$ layers on WK-900 remain nonpolar and hinder the formation of Brønsted acid sites, resulting in the noTable Suppression of ethylene selectivity.

However, a detailed relationship between the structure and acid/base properties of catalysts and ethylene yield in the Lebedev process is not clarified yet [6]. For example, by pyridine adsorption followed by FTIR, we only observed Lewis acid sites for wet-kneaded $\mathrm{SiO}_{2}-\mathrm{MgO}$ catalysts with the absence of Brønsted acid sites, as previously reported $[15,20,51]$ (Figure S5). However, Taifan et al. recently reported the presence of Brønsted acid sites on the surface of wet-kneaded $\mathrm{MgO}-\mathrm{SiO}_{2}$ using diffuse reflectance infrared Fourier transform spectroscopy (DRIFTS) with ammonia as a probe molecule [52]. They claimed that the relatively small size of $\mathrm{NH}_{3}$ could penetrate small pores, while pyridine could not reach them (the kinetic diameters of ammonia and pyridine are 0.26 [53] and $0.57 \mathrm{~nm}$ [54], respectively). We compared the number of acid sites characterized by pyridine adsorption followed by FTIR and $\mathrm{NH}_{3}-\mathrm{TPD}$ (Table S3). For WK-500, pyridine titrates fewer acid sites compared to $\mathrm{NH}_{3}-\mathrm{TPD}$. This could be attributed to the less-accessible acidic sites in the interlamellar spacings for pyridine compared to ammonia. Talc is the one of the predominant phases of WK-500 (Figure 4) and the interlamellar spacings of talc are $0.1-0.6 \mathrm{~nm}$ depending on the degree of hydration $[55,56]$. There is also a possibility that 
the weak acidity of the silanol group on silica and/or on the magnesium silicates could not be probed by pyridine [6].

Previously, forsterite was considered a detrimental magnesium silicate in the Lebedev process. For example, Ochoa et al. indicated that forsterite $\left(\mathrm{MgO}-\mathrm{SiO}_{2}\right.$ prepared by the sol-gel method) is responsible for the ethylene yield [21]. Zhu et al. also reported that crystalline forsterite in a $\mathrm{MgO}-\mathrm{SiO}_{2}$ catalyst (silica gel impregnated by magnesium nitrate hydrate) is inclined toward the formation of byproducts such as ethylene [51]. However, in our results, forsterite on a wet-kneaded $\mathrm{SiO}_{2}-\mathrm{MgO}$ catalyst, together with stevensite, showed not only significantly reduced ethylene formation but also greater selectivity to butadiene. In the Lebedev process, it is reported that a balance between the acidic and basic sites of the catalyst is key for increasing butadiene selectivity $[15,20,57]$. Szabó et al. recently showed that the catalytic activity is highly dependent on the basicity of the non-metalpromoted $\mathrm{MgO}-\mathrm{SiO}_{2}$ catalysts [47]. The basicity of wet-kneaded $\mathrm{SiO}_{2}-\mathrm{MgO}$ catalysts was characterized using $\mathrm{CO}_{2}$ as a probe molecule (the kinetic diameter of $\mathrm{CO}_{2}=0.33 \mathrm{~nm}$ [58]) (Table S3). Interestingly, the $\mathrm{CO}_{2}-\mathrm{TPD}$ results indicated that, despite its low surface area, WK-900 exhibited a higher number of basic sites than WK-800. As the WK-900 catalyst mainly composed of forsterite and stevensite only decorates its grain boundary, the TPD result indicates that forsterite can provide adsorption sites for acidic molecules such as $\mathrm{CO}_{2}$. Recently, Sato et al. reported that the catalytic function of the edges (stevensite) are different from the surfaces of clay minerals such as saponite, which is a structural analogous to our stevensite/forsterite materials [59]. The catalytic performance of WK-900, especially for forsterite, thus, must be considered together with stevensite.

Finally, to verify that the performance of catalyst materials can be directly related to the structure of the fresh samples, we performed a PXRD study of the samples after catalytic testing. The diffractograms of spent catalysts are identical to the fresh ones (Figure S6), suggesting that catalytic testing does not alter the long-range order of the materials. In addition, we monitored the catalytic conversion for $24 \mathrm{~h}$ time-on-stream and found that there are only $2 \%$ difference between the initial and final ethanol conversions, which demonstrates that the active sites do not change their nature or significantly deactivate in the studied time frame (Figure S7).

\section{Conclusions}

Wet-kneaded $\mathrm{SiO}_{2}-\mathrm{MgO}$ catalysts exhibit superior catalytic performance when compared to physical mixtures of $\mathrm{SiO}_{2}$ and $\mathrm{MgO}$ owing to the surface magnesium silicates formed during wet-kneading. An increase in the calcination temperature promotes the formation of amorphous hydrous magnesium silicates and structurally ill-defined lizardite on the surface of wet-kneaded catalysts, which are responsible for ethylene formation. Notably, forsterite, which was decorated with stevensite at the edge of grains, showed noteworthy catalytic performance for butadiene with reduced ethylene selectivity. In view of our findings, it is demonstrated that a delicate balance of different magnesium silicates is crucial for acid-base properties and the corresponding catalytic performance in the Lebedev process. The insights thus gained in the structure-activity relation for the magnesium silicates formed during catalyst preparation can enable further optimization for the selective ethanol-to-butadiene process.

Supplementary Materials: The following are available online at https:/ /www.mdpi.com/2079-499 1/11/3/579/s1, Figure S1: SEM images of wet-kneading precursors, Figure S2: pore size distribution of wet-kneaded catalysts, Figure S3: solid-state ${ }^{1} \mathrm{H}$ SE NMR of wet-kneading precursors, Figure S4: detailed activity test results of wet-kneaded catalysts at different LHSVs, Figure S5: the FT-IR spectra after pyridine adsorption, and $\mathrm{NH}_{3}-$ and $\mathrm{CO}_{2}-\mathrm{TPD}-\mathrm{MS}$ signals as a function of desorption temperature, Figure S6: PXRD patterns of spent wet-kneaded $\mathrm{SiO}_{2}-\mathrm{MgO}$ catalysts after reaction, Figure S7: stability test for WK-500 catalyst, Table S1: Summary of ${ }^{1} \mathrm{H}-{ }^{29}$ Si CP MAS NMR, Table S2: Activity test results of a physical mixture $\mathrm{SiO}_{2}-\mathrm{MgO}$ catalyst, Table S3: summary of ethanol conversion, ethylene selectivity, pyridine-IR, and $\mathrm{NH}_{3}-$ and $\mathrm{CO}_{2}-\mathrm{TPD}$ results. 
Author Contributions: Conceptualization, S.-H.C. and J.R.-M.; catalyst preparation, S.-H.C.; characterization, S.-H.C. and E.A.-H. (solid-state NMR), T.S. (SEM, PXRD, and $\mathrm{N}_{2}$ physisorption), I.M. $\left(\mathrm{NH}_{3}-\right.$ and $\left.\mathrm{CO}_{2}-\mathrm{TPD}\right)$, and S.T. (pyridine-IR), evaluation of catalytic performance, A.R.; data analysis, S.-H.C., T.S., E.A.-H., I.M., T.S., J.G. and J.R.-M.; writing-original draft preparation, S.-H.C. and J.R.-M.; writing-review and editing, S.-H.C., T.S., E.A.-H., I.M., T.S., J.G., and J.R.-M. All authors have read and agreed to the published version of the manuscript.

Funding: Funding was provided by King Abdullah University of Science and Technology (KAUST).

Data Availability Statement: The data presented in this study are available on request from the corresponding authors.

Acknowledgments: We acknowledge Christian G. Canlas (KAUST Core Labs) for the technical support for solid-state NMR.

Conflicts of Interest: The authors declare no conflict of interest.

\section{References}

1. Bruijnincx, P.C.A.; Weckhuysen, B.M. Shale Gas Revolution: An Opportunity for the Production of Biobased Chemicals? Angew. Chemie Int. Ed. 2013, 52, 11980-11987. [CrossRef]

2. Angelici, C.; Weckhuysen, B.M.; Bruijnincx, P.C.A. Chemocatalytic Conversion of Ethanol into Butadiene and Other Bulk Chemicals. ChemSusChem 2013, 6, 1595-1614. [CrossRef]

3. Cespi, D.; Passarini, F.; Vassura, I.; Cavani, F. Butadiene from biomass, a life cycle perspective to address sustainability in the chemical industry. Green Chem. 2016, 18, 1625-1638. [CrossRef]

4. Makshina, E.V.; Dusselier, M.; Janssens, W.; Degrève, J.; Jacobs, P.A.; Sels, B.F. Review of old chemistry and new catalytic advances in the on-purpose synthesis of butadiene. Chem. Soc. Rev. 2014, 43, 7917-7953. [CrossRef] [PubMed]

5. Shylesh, S.; Gokhale, A.A.; Scown, C.D.; Kim, D.; Ho, C.R.; Bell, A.T. From Sugars to Wheels: The Conversion of Ethanol to 1,3-Butadiene over Metal-Promoted Magnesia-Silicate Catalysts. ChemSusChem 2016, 9, 1462-1472. [CrossRef] [PubMed]

6. Pomalaza, G.; Arango Ponton, P.; Capron, M.; Dumeignil, F. Ethanol-to-butadiene: The reaction and its catalysts. Catal. Sci. Technol. 2020, 10, 4860-4911. [CrossRef]

7. Sharma, B.; Larroche, C.; Dussap, C.-G. Comprehensive assessment of 2G bioethanol production. Bioresour. Technol. 2020, 313, 123630. [CrossRef] [PubMed]

8. Quattlebaum, W.M.; Toussaint, W.J.; Dunn, J.T. Deoxygenation of Certain Aldehydes and Ketones: Preparation of Butadiene and Styrene. J. Am. Chem. Soc. 1947, 69, 593-599. [CrossRef]

9. Kyriienko, P.I.; Larina, O.V.; Soloviev, S.O.; Orlyk, S.M.; Calers, C.; Dzwigaj, S. Ethanol Conversion into 1,3-Butadiene by the Lebedev Method over MTaSiBEA Zeolites (M = Ag, Cu, Zn). ACS Sustain. Chem. Eng. 2017, 5, 2075-2083. [CrossRef]

10. Yan, T.; Dai, W.; Wu, G.; Lang, S.; Hunger, M.; Guan, N.; Li, L. Mechanistic Insights into One-Step Catalytic Conversion of Ethanol to Butadiene over Bifunctional Zn-Y/Beta Zeolite. ACS Catal. 2018, 8, 2760-2773. [CrossRef]

11. Taifan, W.E.; Li, Y.; Baltrus, J.P.; Zhang, L.; Frenkel, A.I.; Baltrusaitis, J. Operando Structure Determination of Cu and Zn on Supported $\mathrm{MgO} / \mathrm{SiO} 2$ Catalysts during Ethanol Conversion to 1,3-Butadiene. ACS Catal. 2019, 9, 269-285. [CrossRef]

12. Cabello González, G.M.; Concepción, P.; Villanueva Perales, A.L.; Martínez, A.; Campoy, M.; Vidal-Barrero, F. Ethanol conversion into 1,3-butadiene over a mixed Hf-Zn catalyst: Effect of reaction conditions and water content in ethanol. Fuel Process. Technol. 2019, 193, 263-272. [CrossRef]

13. Ochoa, J.V.; Malmusi, A.; Recchi, C.; Cavani, F. Understanding the Role of Gallium as a Promoter of Magnesium Silicate Catalysts for the Conversion of Ethanol into Butadiene. ChemCatChem 2017, 9, 2128-2135. [CrossRef]

14. Angelici, C.; Velthoen, M.E.Z.; Weckhuysen, B.M.; Bruijnincx, P.C.A. Effect of preparation method and CuO promotion in the conversion of ethanol into 1,3-butadiene over SiO2-MgO catalysts. ChemSusChem 2014, 1-12. [CrossRef]

15. Angelici, C.; Velthoen, M.E.Z.; Weckhuysen, B.M.; Bruijnincx, P.C.A. Influence of acid-base properties on the Lebedev ethanol-tobutadiene process catalyzed by SiO2-MgO materials. Catal. Sci. Technol. 2015, 5, 2869-2879. [CrossRef]

16. Taifan, W.E.; Bučko, T.; Baltrusaitis, J. Catalytic conversion of ethanol to 1,3-butadiene on MgO: A comprehensive mechanism elucidation using DFT calculations. J. Catal. 2017, 346, 78-91. [CrossRef]

17. Abdulrazzaq, H.T.; Rahmani Chokanlu, A.; Frederick, B.G.; Schwartz, T.J. Reaction Kinetics Analysis of Ethanol Dehydrogenation Catalyzed by $\mathrm{MgO}-\mathrm{SiO}_{2}$. ACS Catal. 2020, 10, 6318-6331. [CrossRef]

18. Natta, G.; Rigamonti, R. Studio roentgenografico e chimico dei catalizzatori usati per la produzione del butadiene dall'alcool. Chim. Ind. 1947, 29, 239-243.

19. Chung, S.-H.; Angelici, C.; Hinterding, S.O.M.; Weingarth, M.; Baldus, M.; Houben, K.; Weckhuysen, B.M.; Bruijnincx, P.C.A. Role of Magnesium Silicates in Wet-Kneaded Silica-Magnesia Catalysts for the Lebedev Ethanol-to-Butadiene Process. ACS Catal. 2016, 6, 4034-4045. [CrossRef]

20. Janssens, W.; Makshina, E.V.; Vanelderen, P.; De Clippel, F.; Houthoofd, K.; Kerkhofs, S.; Martens, J.A.; Jacobs, P.A.; Sels, B.F. Ternary Ag/MgO-SiO2 Catalysts for the Conversion of Ethanol into Butadiene. ChemSusChem 2015, 8, 994-1008. [CrossRef] [PubMed] 
21. Velasquez Ochoa, J.; Bandinelli, C.; Vozniuk, O.; Chieregato, A.; Malmusi, A.; Recchi, C.; Cavani, F. An analysis of the chemical, physical and reactivity features of $\mathrm{MgO}-\mathrm{SiO} 2$ catalysts for butadiene synthesis with the Lebedev process. Green Chem. 2016, 18, 1653-1663. [CrossRef]

22. Van Rossum, B.-J.; Förster, H.; de Groot, H.J.M. High-Field and High-Speed CP-MAS13C NMR Heteronuclear Dipolar-Correlation Spectroscopy of Solids with Frequency-Switched Lee-Goldburg Homonuclear Decoupling. J. Magn. Reson. 1997, 124, 516-519. [CrossRef]

23. Li, S.; Men, Y.; Wang, J.; Liu, S.; Wang, X.; Ji, F.; Chai, S.; Song, Q. Morphological control of inverted MgO-SiO 2 composite catalysts for efficient conversion of ethanol to 1,3-butadiene. Appl. Catal. A Gen. 2019, 577, 1-9. [CrossRef]

24. Van Aken, P.A.; Langenhorst, F. Nanocrystalline, porous periclase aggregates as product of brucite dehydration. Eur. J. Mineral. 2001, 13, 329-341. [CrossRef]

25. Ball, M.C.; Taylor, H.F.W. The dehydration of brucite. Mineral. Mag. J. Mineral. Soc. 1961, 32, 754-766. [CrossRef]

26. Yamaguchi, G.; Tokuda, T. Electron Microscopic Study of the Dehydration of Brucite and the Recrystallization of Periclase upon Further Heating. Bull. Chem. Soc. Jpn. 1964, 37, 399-403. [CrossRef]

27. Sing, K.S.W.; Everett, D.H.; Haul, R.A.W.; Moscou, L.; Pierotti, R.A.; Rouquerol, J.; Siemieniewska, T. Reporting physisorption data for gas/solid systems with special reference to the determination of surface area and porosity. Pure Appl. Chem. 1985, 57, 603-619. [CrossRef]

28. Kim, H.N.; Lee, S.K. Atomic structure and dehydration mechanism of amorphous silica: Insights from ${ }^{29} \mathrm{Si}$ and ${ }^{1} \mathrm{H}$ solid-state MAS NMR study of SiO2 nanoparticles. Geochim. Cosmochim. Acta 2013, 120, 39-64. [CrossRef]

29. Sorte, E.G.; Rimsza, J.M.; Alam, T.M. Computational and Experimental 1H-NMR Study of Hydrated Mg-Based Minerals. Molecules 2020, 25, 933. [CrossRef]

30. Dumas, A.; Martin, F.; Le Roux, C.; Micoud, P.; Petit, S.; Ferrage, E.; Brendlé, J.; Grauby, O.; Greenhill-Hooper, M. Phyllosilicates synthesis: A way of accessing edges contributions in NMR and FTIR spectroscopies. Example of synthetic talc. Phys. Chem. Miner. 2013, 40, 361-373. [CrossRef]

31. Phillips, B.L.; Burnley, P.C.; Worminghaus, K.; Navrotsky, A. 29 Si and 1 H NMR spectroscopy of high-pressure hydrous magnesium silicates. Phys. Chem. Miner. 1997, 24, 179-190. [CrossRef]

32. Grüninger, H.; Liu, Z.; Brauckmann, J.O.; Fei, H.; Ballaran, T.B.; Martin, T.; Siegel, R.; Kentgens, A.P.M.; Frost, D.J.; Senker, J. Hydroxyl Defects and Oxide Vacancies within Ringwoodite-toward Understanding the Defect Chemistry of Spinel-Type Oxides. J. Phys. Chem. C 2020, 124, 12001-12009. [CrossRef]

33. Wu, S.; Peng, Y.-K.; Chen, T.-Y.; Mo, J.; Large, A.; McPherson, I.; Chou, H.-L.; Wilkinson, I.; Venturini, F.; Grinter, D.; et al. Removal of Hydrogen Poisoning by Electrostatically Polar MgO Support for Low-Pressure NH3 Synthesis at a High Rate over the Ru Catalyst. ACS Catal. 2020, 10, 5614-5622. [CrossRef]

34. Nishizawa, J.; Ikeda-Fukazawa, T. Surface structures and properties of forsterite in crystalline and glassy states. Chem. Phys. Lett. 2019, 714, 197-201. [CrossRef]

35. Liu, T.; Gautam, S.; Wang, H.-W.; Anovitz, L.M.; Mamontov, E.; Allard, L.F.; Cole, D.R. Structure and dynamics of water on the forsterite surface. Phys. Chem. Chem. Phys. 2018, 20, 27822-27829. [CrossRef] [PubMed]

36. Poirier, M.; Millot, Y.; Silva Gomes, E.; Jaber, M.; Herledan, V.; Laugel, G.; Micoud, P.; Martin, F.; Lauron-Pernot, H.; Toulhoat, H. Complementarity of Density Functional Theory and Nuclear Magnetic Resonance Tools To Probe the Nano-Layered Silicates Surface Chemistry and Morphology. J. Phys. Chem. C 2020, 124, 267-286. [CrossRef]

37. Temuujin, J.; Okada, K.; MacKenzie, K.J.D. Role of Water in the Mechanochemical Reactions of MgO-SiO2 Systems. J. Solid State Chem. 1998, 138, 169-177. [CrossRef]

38. D'Espinose de la Caillerie, J.-B.; Kermarec, M.; Clause, O.; de la Caillerie, E.; Kermarec, M.; Clause, O. 29Si NMR Observation of an Amorphous Magnesium Silicate Formed during Impregnation of Silica with $\mathrm{Mg}(\mathrm{I} 1)$ in Aqueous Solution. J. Phys. Chem 1995, 99, 17273-17281. [CrossRef]

39. Chen, L.; Ye, G.; Zhou, W.; Dijkmans, J.; Sels, B.; Malfliet, A.; Guo, M. Influence of MgO precursors on mechanically activated forsterite synthesis. Ceram. Int. 2015, 41, 12651-12657. [CrossRef]

40. Walling, S.A.; Kinoshita, H.; Bernal, S.A.; Collier, N.C.; Provis, J.L. Structure and properties of binder gels formed in the system $\mathrm{Mg}(\mathrm{OH}) 2-\mathrm{SiO} 2-\mathrm{H} 2 \mathrm{O}$ for immobilisation of Magnox sludge. Dalt. Trans. 2015, 44, 8126-8137. [CrossRef]

41. Davis, M.C.; Brouwer, W.J.; Wesolowski, D.J.; Anovitz, L.M.; Lipton, A.S.; Mueller, K.T. Magnesium silicate dissolution investigated by 29Si MAS, 1H-29Si CPMAS, 25Mg QCPMG, and 1H-25Mg CP QCPMG NMR. Phys. Chem. Chem. Phys. 2009, 11, 7013. [CrossRef]

42. Chabrol, K.; Gressier, M.; Pebere, N.; Menu, M.-J.; Martin, F.; Bonino, J.-P.; Marichal, C.; Brendle, J. Functionalization of synthetic talc-like phyllosilicates by alkoxyorganosilane grafting. J. Mater. Chem. 2010, 20, 9695. [CrossRef]

43. MacKenzie, K.J.D.; Bradley, S.; Hanna, J.V.; Smith, M.E. Magnesium analogues of aluminosilicate inorganic polymers (geopolymers) from magnesium minerals. J. Mater. Sci. 2013, 48, 1787-1793. [CrossRef]

44. Bernard, E.; Lothenbach, B.; Chlique, C.; Wyrzykowski, M.; Dauzères, A.; Pochard, I.; Cau-Dit-Coumes, C. Characterization of magnesium silicate hydrate (M-S-H). Cem. Concr. Res. 2019, 116, 309-330. [CrossRef]

45. Magi, M.; Lippmaa, E.; Samoson, A.; Engelhardt, G.; Grimmer, a.R. Solid-state high-resolution silicon-29 chemical shifts in silicates. J. Phys. Chem. 1984, 88, 1518-1522. [CrossRef] 
46. Stebbins, J.F.; Panero, W.R.; Smyth, J.R.; Frost, D.J. Forsterite, wadsleyite, and ringwoodite (Mg2SiO4): 29Si NMR constraints on structural disorder and effects of paramagnetic impurity ions. Am. Mineral. 2009, 94, 626-629. [CrossRef]

47. Szabó, B.; Novodárszki, G.; Pászti, Z.; Domján, A.; Valyon, J.; Hancsók, J.; Barthos, R. MgO-SiO2 Catalysts for the Ethanol to Butadiene Reaction: The Effect of Lewis Acid Promoters. ChemCatChem 2020, 12, 5686-5696. [CrossRef]

48. Chabanas, M.; Quadrelli, E.A.; Fenet, B.; Copéret, C.; Thivolle-Cazat, J.; Basset, J.-M.; Lesage, A.; Emsley, L. Molecular Insight Into Surface Organometallic Chemistry Through the Combined Use of 2D HETCOR Solid-State NMR Spectroscopy and Silsesquioxane Analogues. Angew. Chemie Int. Ed. 2001, 40, 4493. [CrossRef]

49. Kvisle, S.; Aguero, A.; Sneeden, R.P.A. Transformation of ethanol into 1,3-butadiene over magnesium oxide/silica catalysts. Appl. Catal. 1988, 43, 117-131. [CrossRef]

50. Larina, O.V.; Kyriienko, P.I.; Trachevskii, V.V.; Vlasenko, N.V.; Soloviev, S.O. Effect of Mechanochemical Treatment on Acidic and Catalytic Properties of MgO-SiO2 Composition in the Conversion of Ethanol To 1,3-Butadiene. Theor. Exp. Chem. 2016, 51, 387-393. [CrossRef]

51. Zhu, Q.; Wang, B.; Tan, T. Conversion of Ethanol and Acetaldehyde to Butadiene over $\mathrm{MgO}^{-\mathrm{SiO}_{2}}$ Catalysts: Effect of Reaction Parameters and Interaction between $\mathrm{MgO}$ and $\mathrm{SiO}_{2}$ on Catalytic Performance. ACS Sustain. Chem. Eng. 2017, 5, 722-733. [CrossRef]

52. Taifan, W.E.; Baltrusaitis, J. In Situ Spectroscopic Insights on the Molecular Structure of the $\mathrm{MgO} / \mathrm{SiO}_{2} \mathrm{Catalytic}$ Active Sites during Ethanol Conversion to 1,3-Butadiene. J. Phys. Chem. C 2018, 122, 20894-20906. [CrossRef]

53. Kanezashi, M.; Yamamoto, A.; Yoshioka, T.; Tsuru, T. Characteristics of ammonia permeation through porous silica membranes. AIChE J. 2009, 59, 1204-1212. [CrossRef]

54. Bräuer, P.; Ng, P.L.; Situmorang, O.; Hitchcock, I.; D'Agostino, C. Effect of Al content on number and location of hydroxyl acid species in zeolites: A DRIFTS quantitative protocol without the need for molar extinction coefficients. RSC Adv. 2017, 7, 52604-52613. [CrossRef]

55. Carmignano, O.; Vieira, S.; Brandão, P.R.; Bertoli, A.; Lago, R. Serpentinites: Mineral Structure, Properties and Technological Applications. J. Braz. Chem. Soc. 2020, 31, 2-14. [CrossRef]

56. Lainé, M.; Balan, E.; Allard, T.; Paineau, E.; Jeunesse, P.; Mostafavi, M.; Robert, J.-L.; Le Caër, S. Reaction mechanisms in swelling clays under ionizing radiation: Influence of the water amount and of the nature of the clay mineral. RSC Adv. 2017, 7, 526-534. [CrossRef]

57. Huang, X.; Men, Y.; Wang, J.; An, W.; Wang, Y. Highly active and selective binary $\mathrm{MgO}-\mathrm{SiO}_{2}$ catalysts for the production of 1,3-butadiene from ethanol. Catal. Sci. Technol. 2017, 7, 168-180. [CrossRef]

58. Yang, J.; Zhao, Q.; Xu, H.; Li, L.; Dong, J.; Li, J. Adsorption of $\mathrm{CO}_{2}, \mathrm{CH}_{4}$, and $\mathrm{N}_{2}$ on Gas Diameter Grade Ion-Exchange Small Pore Zeolites. J. Chem. Eng. Data 2012, 57, 3701-3709. [CrossRef]

59. Sato, K.; Hunger, M. Carbon dioxide adsorption in open nanospaces formed by overlap of saponite clay nanosheets. Commun. Chem. 2020, 3, 91. [CrossRef] 